Article

\title{
Summary-Based Methylome-Wide Association Analyses Suggest Potential Genetically Driven Epigenetic Heterogeneity of Alzheimer's Disease
}

\author{
Alireza Nazarian *, Anatoliy I. Yashin and Alexander M. Kulminski * (B) \\ Biodemography of Aging Research Unit, Social Science Research Institute, Duke University, Durham, NC 27705, \\ USA; aiy@duke.edu \\ * Correspondence: alireza.nazarian@duke.edu (A.N.); kulminsk@duke.edu (A.M.K.)
}

Received: 14 February 2020; Accepted: 13 May 2020; Published: 15 May 2020

\begin{abstract}
Alzheimer's disease (AD) is a progressive neurodegenerative disorder with no curative treatment available. Exploring the genetic and non-genetic contributors to AD pathogenesis is essential to better understand its underlying biological mechanisms, and to develop novel preventive and therapeutic strategies. We investigated potential genetically driven epigenetic heterogeneity of $\mathrm{AD}$ through summary data-based Mendelian randomization (SMR), which combined results from our previous genome-wide association analyses with those from two publicly available methylation quantitative trait loci studies of blood and brain tissue samples. We found that 152 probes corresponding to 113 genes were epigenetically associated with $\mathrm{AD}$ at a Bonferroni-adjusted significance level of 5.49E-07. Of these, 10 genes had significant probes in both brain-specific and blood-based analyses. Comparing males vs. females and hypertensive vs. non-hypertensive subjects, we found that 22 and 79 probes had group-specific associations with $\mathrm{AD}$, respectively, suggesting a potential role for such epigenetic modifications in the heterogeneous nature of AD. Our analyses provided stronger evidence for possible roles of four genes (i.e., AIM2, C16orf80, DGUOK, and ST14) in $\mathrm{AD}$ pathogenesis as they were also transcriptionally associated with AD. The identified associations suggest a list of prioritized genes for follow-up functional studies and advance our understanding of AD pathogenesis.
\end{abstract}

Keywords: neurodegenerative diseases; dementia; aging; GWAS; mQTLs; eQTLs; Alzheimer's disease; Alzheimer's disease pathogenesis; methylome-wide association analyses; summary data-based mendelian randomization

\section{Introduction}

Alzheimer's disease (AD) is the major cause of dementia and is projected to affect more than 13 million people in the United States by 2050, thus imposing huge health and economic burdens [1,2] Late onset $\mathrm{AD}$ is believed to be a multifactorial disease caused by complex interactions between various genetic and non-genetic factors [3]. Many genetic variants mapped to several chromosomal regions and genes have thus far been associated with AD by genome-wide association studies (GWAS) $[4,5]$; although, the vast majority of $\mathrm{AD}$ cases cannot be etiologically attributed to these variants $[2,6]$ Also, none of non-genetic AD-associated factors (e.g., age, cardiovascular risk factors, head trauma, depression, and educational attainment) has been proven to have a strong causal relationship with $\operatorname{AD}[7,8]$.

Epigenetic modifications of gene expression in interaction with non-genetic factors are hypothesized to contribute to AD development [6,9], particularly in light of the heterogeneous clinical manifestations of AD observed among patients with similar or identical genetic backgrounds [10]. 
The potential role of epigenetic mechanisms in $\mathrm{AD}$ pathogenesis has been widely investigated in cell lines, mouse models, post-mortem brain tissue, and blood cells [6,10-13]. Several studies have explored the global DNA methylation in AD cases compared with controls, although their findings have been inconclusive, with some reporting global hypomethylation in AD, some suggesting global hypermethylation in $\mathrm{AD}$, and the others reporting no significant differences between cases and controls [12]. Previous studies have also provided many lines of evidence of associations between $\mathrm{AD}$ and gene-specific epigenetic modifications. They mainly investigated the DNA methylation and histone modification differences between $\mathrm{AD}$ cases and unaffected controls using candidate gene or genome-wide analysis approaches (e.g., pyrosequencing and array hybridization) which revealed AD-associated epigenetic modifications in some well-known AD genes, such as amyloid- $\beta$ precursor protein $(A P P)$, Microtubule Associated Protein Tau (MAPT) [14], and Apolipoprotein E (APOE) [15], as well as in other genes [12]. For instance, Iwata et al. discovered CpG hypermethylation in APP and MAPT in post-mortem brain samples from AD patients, which were suggested to contribute to neural dysfunction and AD development [14]. Foraker et al. found that AD patients had a lower mean methylation level in $76 \mathrm{CpG}$ sites across $A P O E$ gene compared with age-matched controls when hippocampus and frontal lobe samples were analyzed. However, APOE methylation was not statistically different between cases and controls in samples obtained from their cerebellum [15].

In most cases, epigenetically dysregulated genes were uniquely found in a single study $[6,10,12,13]$, although AD-associated epigenetic modifications of some genes have been replicated in independent studies. For instance, several studies have reported CpG hypermethylation in the ANK1 gene in different brain regions, such as entorhinal and prefrontal cortices, superior temporal gyrus, and/or hippocampus in AD patients [16-18]. Hypermethylated regions overlapping DUSP22 gene were previously detected in entorhinal and dorsolateral prefrontal cortices and/or hippocampus of AD affected individuals $[18,19]$, and CpG hypermethylation of SORBS3 was detected in the cerebral cortex of AD patients and transgenic AD mouse models [11,20]. Moreover, differentially methylated regions overlapping $C D H 23, R H B D F 2$, and $R P L 13$ genes were reported in previous studies $[16,17,21]$. The mRNA expressions of these genes were also found to be altered in AD patients [16]. In addition, several genes whose associations with AD were replicated by independent GWAS [2], such as $A B C A 7$, BIN1, CLU, HLA-DRB5, SLC24A4, and SORL1, are epigenetically implicated in AD as well [16,22,23]. The case-control studies and cell/animal models may not, however, reflect genetic contributions to AD-associated epigenetic modifications as they are more likely to identify the environmentally induced epigenetic alterations [6,9]. In addition to the studies using individual-level data, several epigenetically AD-associated genes, such as BIN1, APOC1, HLA-DRB1, HLA-DRB5, and TOMM40, have been reported by summary data-based analyses $[24,25]$ which reflect genetically driven (i.e., through cis acting variants) epigenetic alterations [26].

In this study, we performed methylome-wide association (MWA) analyses of AD using the summary data-based Mendelian randomization (SMR) method [26] to investigate genetically driven epigenetic contributors to AD pathogenesis. Instead of analyzing individual-level data, the SMR method integrates the summary results from previous GWAS $[27,28]$ and methylation quantitative trait loci (mQTLs) studies using blood samples [29] and brain tissue [30] in order to identify associations between $\mathrm{AD}$ and methylation alterations that may mediate the genetic associations examined by GWAS. Central to our study was to investigate potential genetically driven epigenetic heterogeneity of AD. Therefore, summary results from our previous GWAS which aimed to analyze genetic heterogeneity of $\mathrm{AD}$ in contrasting groups of subjects stratified based on their sex and history of hypertension (HTN) were used for our MWA analyses. Sex has been identified as a risk factor for AD and there are many reports highlighting sex disparities in epidemiological and clinical features of AD [31-37]. HTN is also a major cardiovascular risk factor for AD that may be involved in initiation and progression of the disease by causing structural and functional damages to cerebral microvasculature and promoting amyloid plaques formation $[8,38,39]$. By detecting several group-specific AD-associated single-nucleotide polymorphisms (SNPs) at $\mathrm{P}<5 \mathrm{E}-06$, our GWAS suggested that differences in the genetic architecture 
of AD between these contrasting groups may differentially contribute to AD pathogenesis $[27,28]$. Thus, the current study using summary results from these two GWAS may provide novel insights into potential genetically driven epigenetic heterogeneity of $\mathrm{AD}$. To further validate significant findings, we compared our MWA results with those from our previous transcriptome-wide association (TWA) analyses of AD $[27,28]$ that implemented the SMR method using the same GWAS summary results along with data from blood-based [40] and brain-specific [30,41] expression quantitative trait loci (eQTLs) studies.

\section{Methods}

\subsection{GWAS Data}

This study makes use of the results of our previous genome-wide association meta-analyses [27,28]. Briefly, these meta-analyses were performed using genotype and phenotype data from four independent datasets: (1) Cardiovascular Health Study (CHS) [42]; (2) Framingham Heart Study (FHS) [43,44]; (3) Late-Onset Alzheimer's Disease Family Study (LOADFS) from the National Institute on Aging [45], available to the research community through the dbGaP repository (https://www.ncbi.nlm.nih.gov/gap); and (4) Health and Retirement Study (HRS) [46], which can be accessed through dbGaP and the University of Michigan restricted access webpage (http://hrsonline.isr.umich.edu/index.php?p=data). These meta-analyses were performed under five analysis plans in which the genetic basis of AD was investigated among: (1) all subjects in each dataset, (2) only males, (3) only females [27], (4) only subjects with a history of HTN, or (5) only subjects with no history of HTN [28]. AD patients were mainly diagnosed clinically based on neurologic findings (e.g., using National Institute of Neurological and Communicative Disorders and Stroke-Alzheimer's Disease and Related Disorders Association (NINCDS-ADRDA) criteria [47]) and were either identified directly (LOADFS and FHS datasets) or reported indirectly (CHS and HRS datasets) through the International Classification of Disease codes, Ninth revision (i.e., ICD-9:331.0 code). The numbers of AD cases were 2741, 952, 1789, 1262, and 796 under plans 1-5, respectively; and the numbers of unaffected controls were 14739, 6337, 8402, 9608 , and 4010 , respectively. The studied subjects were all of Caucasian ancestry to make samples more homogeneous.

For each analysis plan, the additive genetic associations of $\sim 2$ million SNPs with AD were investigated by fitting logistic regression (CHS and HRS cohorts with population-based design) [48] or generalized mixed logistic regression (LOADFS and FHS cohorts with family-based design) [49] models. The top five principal components of genotype data, birth year, and sex (except plans 2 and 3) of subjects were considered as fixed-effects covariates. In the case of LOADFS and FHS cohorts, family identifier was also included as a random-effects covariate in the fitted models to adjust for potential confounding from family structure. Individual GWAS results from the four datasets were then combined by inverse-variance meta-analysis [50]. Under plans $2-5$ that aimed to investigate the genetic heterogeneity of AD through stratified analyses of datasets under consideration, group-specific SNPs effects were identified by a Wald chi-square test $(\mathrm{df}=1)$ [51] which was performed for any SNPs with significant association signals in only one of the contrasting groups in order to determine whether the SNPs odds ratios were significantly different between males and females (plans 2 and 3) [27] and between hypertensive and non-hypertensive subjects (plans 4 and 5) [28].

$$
\chi^{2}=\frac{\left(b_{1}-b_{2}\right)^{2}}{s e_{1}^{2}+s e_{2}^{2}}
$$

where $b_{1}\left(s e_{1}\right)$ and $b_{2}\left(s e_{2}\right)$ are the beta coefficients (and their standard errors) of a SNP in each of the two contrasting groups. 


\section{2. $m Q T L s$ Data}

The summary results from two previous mQTLs studies using blood samples $(n=1980)$ [29] and human brain tissue ( $n=1160$ from a meta-analysis of three independent brain-specific mQTLs data of mostly dorsolateral prefrontal cortex and fetal brain samples) [30] were also used for our analyses. The mQTLs studies provided genome-wide CpG methylation data using the Illumina Human Methylation $450 \mathrm{~K}$ array. The mQTLs data in the format compatible for MWA analyses can be downloaded at: https://cnsgenomics.com/software/smr/\#DataResource. The annotation of probes was in accordance with the Illumina support files for Human Methylation 450K array. Probes which were located in the inter-genic regions (IGRs) (i.e., not located within any gene or within $1.5 \mathrm{~kb}$ of the transcription start site of any gene [52]) were annotated to their closest genes.

\subsection{MWA Analysis}

Under each of the five analysis plans, two sets of MWA analyses (i.e., blood-based and brain-specific) were performed by combining the results from our GWAS with publicly available summary results from the two mQTLs studies. MWA analyses were performed by the SMR package (v 0.710) [26] to identify SNPs that might be pleiotropically associated with AD and DNA methylation changes. The SMR package was run using default input arguments. Probes that had at least one significant mQTL (i.e., a SNP with $P_{\text {mQTL }}<5 E-08$ ) that was also among the SNPs in our GWAS were included. This resulted in the inclusion of sets of up to 90,357 and 90,848 probes with significant cis-mQTLs from blood-based and brain-specific mQTLs studies under the five analysis plans.

Associations of any probes with AD were first sought through a SMR test, and significant associations were determined at a Bonferroni-adjusted significance level of 5.49E-07 (i.e., 0.05/91000) to account for multiple comparisons. Probes with significant $\mathrm{P}_{\text {SMR }}$ were then selected for heterogeneity in dependent instruments (HEIDI) testing to identify associations that were likely to arise from the pleiotropic effects of a single locus on both methylation changes and AD status (i.e., probes with $P_{\text {HEIDI }} \geq 0.05$ ) and not from the linkage between adjacent variants that affected AD susceptibility and methylation patterns separately (i.e., probes with $P_{\text {HEIDI }}<0.05$ ) [26]. Here, HRS was used as the reference panel for estimating pair-wise linkage disequilibrium and SNP clumping.

To examine the consistency of probe effects in blood-based and brain-specific analyses, the $\mathrm{b}_{\mathrm{SMR}}$ of any probes were compared between these analyses using the chi-square test mentioned above in the GWAS data section. In addition, probes that were detected in either males or females and in either hypertensive or non-hypertensive groups were subject to the chi-square test to find out whether their $\mathrm{b}_{\mathrm{SMR}}$ were significantly different between the two contrasting groups (i.e., they had group-specific effects).

Finally, lists of AD-associated genes from MWA analyses were compared to those from our previous blood-based and brain-specific TWA analyses $[27,28]$ to identify any overlaps between epigenetically and transcriptionally AD-associated genes.

\subsection{Pathway Enrichment Analysis}

Pathway enrichment analysis was performed to correlate nominally AD-associated genes in our MWA results with biological processes that might contribute to AD pathogenesis. Pathway-based analyses were performed by the GSA-SNP2 (i.e., gene set analysis-single nucleotide polymorphism2) package [53] using 1329 canonical pathways provided by the Broad Institute gene set enrichment analysis (GSEA) website [54] based on information from several pathway databases such as Kyoto Encyclopedia of Genes and Genomes (KEGG) [55], REACTOME pathway knowledgebase [56], Pathway Interaction Database (PID) [57], and Matrisome Project [58]. Significant AD-associated pathways were determined using plan-specific false discovery rates (FDR) [59] at which the numbers of possible false-positively detected pathways were smaller than 1 (i.e., FDR levels between 0.05 and 0.25 ). 


\subsection{Ethics Approval}

This study focuses on secondary analysis of data obtained from dbGaP and the University of Michigan [42-46] (please see the Supporting Acknowledgment in Additional File 1) and does not involve gathering data from human subjects directly. The study was performed according to the Duke University Institutional Review Board (IRB) guidelines.

\section{Results}

\subsection{Blood-Based MWA Analyses}

We found that $8,31,9,6$ and 84 probes passed both SMR at a Bonferroni-adjusted level of 5.49E-07 ( $\mathrm{P}_{\mathrm{SMR}}$ between 8.73E-20 and 5.26E-07) and HEIDI $\left(\mathrm{P}_{\mathrm{HEIDI}} \geq 0.05\right)$ tests under analysis plans 1-5, respectively (Additional File 1: Table S1). These probes were mapped to 5, 21, 9, 5, and 66 genes (71 chromosomal regions, i.e., cytogenetic bands, in total), respectively. Seventeen genes had more than one significant probe (2-9 probes per gene that were $51-61,765$ base pairs apart and, in most cases, had the same top mQTLs). Top mQTLs corresponding to these probes were nominally significant $\left(6.45 \mathrm{E}-06 \leq \mathrm{P}_{\mathrm{GWAS}}\right)$ in our genome-wide meta-analyses $[27,28]$, except for the cg06750524 probe corresponding to the APOE gene whose top mQTLs had 2.15E- $83 \leq \mathrm{P}_{\mathrm{GWAS}} \leq 8.19 \mathrm{E}-30$ under the five analysis plans of interest.

\subsection{Brain-Specific MWA Analyses}

There were 2, 6, 4, 4, and 27 probes that passed both SMR at a Bonferroni-adjusted threshold of 5.49E-07 ( $\mathrm{P}_{\mathrm{SMR}}$ between 1.52E-12 and 5.17E-07) and HEIDI $\left(\mathrm{P}_{\mathrm{HEIDI}} \geq 0.05\right)$ tests under plans $1-5$, respectively (Additional File 1: Table S2). These probes were mapped to 2, 5, 3, 4, and 24 genes (located in 26 chromosomal regions), respectively. Six genes had more than one significant probe (2-4 probes per gene that were 5-740 base pairs apart and were mostly influenced by the same genetic signal). Again, the top mQTLs corresponding to these probes were nominally significant $\left(4.88 \mathrm{E}-05 \leq \mathrm{P}_{\text {GWAS }}\right)$ in our GWAS except for the one corresponding to cg02613937 probe, which had 3.73E-63 $\leq \mathrm{P}_{\text {GWAS }} \leq$ 9.84E-24. This probe was mapped to the TOMM40 gene, which is near the APOE gene.

\subsection{Comparison of Blood-Based and Brain-Specific MWA Results}

The consistency of blood-based and brain-specific results was examined by comparing the probes effect sizes and directions (i.e., the magnitudes and signs of $b_{\mathrm{SMR}}$ ) between the two analyses. The directions of effects were the same for $\sim 77 \%$ of probes in both analyses and across five plans of interest. When the blood-based and brain-specific $\mathrm{b}_{\mathrm{SMR}}$ were compared using a Wald chi-square test, less than $1 \%$ of probes (i.e., $0.006-0.073 \%$ across the five study plans) had significantly different effects at the Bonferroni-adjusted significance level. Probes corresponding to the following 10 genes were significantly associated with AD in both blood-based and brain-specific analyses (Tables 1 and 2): NANOS2 (plan 2), HLA-DQB2 (plan 3), FAM193B (plan 4), SLC6A7, BPGM, PSTK, KRTAP5-11, LECT1, ZNF598, and C16orf80 (plan 5). All but BPGM and KRTAP5-11 had common probes in the two analyses, with directions of effects being the same and not significantly different at Bonferroni-adjusted level. The top mQTLs in blood-based and brain-specific analyses were the same for probes corresponding to NANOS2, HLA-DQB2, FAM193B, SLC6A7, KRTAP5-11, and ZNF598. 
Table 1. Blood-based methylome-wide association results for genes that had significant probes in both brain-specific and blood-based analyses.

\begin{tabular}{|c|c|c|c|c|c|c|c|c|c|c|c|c|c|c|c|c|c|}
\hline ProbeID & Chr & ProbePos & Gene & SNP & Pos & A1 & Freq & $P_{\text {GWAS }}$ & $P_{\mathrm{mQTL}}$ & $\mathbf{b}_{\text {SMR }}$ & $\mathrm{SE}_{\mathrm{SMR}}$ & $\mathrm{P}_{\text {SMR }}$ & $P_{\text {HEIDI }}$ & $\mathrm{N}_{\text {HEIDI }}$ & Current? & Previous? & Region? \\
\hline \multicolumn{18}{|c|}{ Plan 2: Only Males } \\
\hline $\operatorname{cg} 05206559$ & $19 q 13.32$ & 45913997 & NANOS2 & rs66529687 & 45914171 & A & 0.133 & $1.83 \mathrm{E}-04$ & $2.84 \mathrm{E}-41$ & 0.723 & 0.125 & 7.67E-09 & 3.28E-01 & 20 & G & G & G \\
\hline cg25673584 & $19 q 13.32$ & 45914293 & NANOS2 & rs66529687 & 45914171 & A & 0.133 & $1.83 \mathrm{E}-04$ & 4.40E-30 & 0.849 & 0.152 & $2.45 \mathrm{E}-08$ & 1.23E-01 & 20 & G & G & G \\
\hline cg14192299 & $19 q 13.32$ & 45914381 & NANOS2 & rs66529687 & 45914171 & A & 0.133 & $1.83 \mathrm{E}-04$ & $6.71 \mathrm{E}-42$ & 0.718 & 0.124 & $7.30 \mathrm{E}-09$ & 1.08E-01 & 20 & G & G & G \\
\hline cg19702802 & $19 \mathrm{q} 13.32$ & 45914471 & NANOS2 & rs 66529687 & 45914171 & A & 0.133 & $1.83 \mathrm{E}-04$ & $3.22 \mathrm{E}-39$ & 0.743 & 0.129 & 9.10E-09 & $1.03 \mathrm{E}-01$ & 20 & G & G & G \\
\hline \multicolumn{18}{|c|}{ Plan 3: Only Females } \\
\hline $\operatorname{cg} 10218546$ & 6 p21.32 & 32762046 & $H L A-D Q B 2$ & rs7768538 & 32762044 & C & 0.426 & $6.15 \mathrm{E}-05$ & $1.30 \mathrm{E}-126$ & -0.304 & 0.060 & $3.27 \mathrm{E}-07$ & $6.43 \mathrm{E}-02$ & 20 & S & G & G \\
\hline \multicolumn{18}{|c|}{ Plan 4: Hypertensive Subjects } \\
\hline cg23395749 & $5 q 35.3$ & 177557245 & FAM193B & rs1001530 & 177558514 & G & 0.046 & $3.36 \mathrm{E}-04$ & $2.55 \mathrm{E}-26$ & -0.484 & 0.088 & $3.08 \mathrm{E}-08$ & 8.77E-02 & 5 & $\mathrm{~N}$ & $\mathrm{~S}$ & $\mathrm{~S}$ \\
\hline \multicolumn{18}{|c|}{ Plan 5: Non-hypertensive Subjects } \\
\hline $\operatorname{cg} 08631357$ & $5 q 32$ & 150209647 & SLC6A7 & rs10076748 & 150209303 & A & 0.107 & $1.77 \mathrm{E}-03$ & $1.54 \mathrm{E}-193$ & 0.288 & 0.056 & $3.18 \mathrm{E}-07$ & 2.02E-01 & 20 & $\mathrm{~N}$ & $\mathrm{~N}$ & G \\
\hline cg23891049 & $7 \mathrm{q} 33$ & 134679117 & BPGM & rs73441994 & 134679118 & A & 0.021 & 4.26E-02 & 1.18E-229 & -0.156 & 0.030 & $1.70 \mathrm{E}-07$ & 6.07E-01 & 4 & $\mathrm{~N}$ & $\mathrm{~S}$ & $\mathrm{~s}$ \\
\hline cg24635736 & $10 \mathrm{q} 26.13$ & 122979534 & PSTK & rs2421140 & 123027854 & A & 0.029 & 8.09E-03 & 2.67E-77 & -0.346 & 0.060 & 6.12E-09 & 7.16E-01 & 8 & $\mathrm{~N}$ & $\mathrm{~N}$ & $\mathrm{~N}$ \\
\hline cg05360847 & $11 \mathrm{q} 13.4$ & 71576873 & KRTAP5-11 & rs11827208 & 71578103 & $\mathrm{~T}$ & 0.020 & $1.70 \mathrm{E}-03$ & 3.47E-13 & -0.942 & 0.159 & $3.50 \mathrm{E}-09$ & 2.02E-01 & 4 & $\mathrm{~N}$ & $\mathrm{~N}$ & $\mathrm{~S}$ \\
\hline cg17632299 & 13q14.3 & 52738831 & LECT1 & rs4885947 & 52735009 & $\mathrm{C}$ & 0.037 & $1.23 \mathrm{E}-03$ & 7.51E-54 & 0.592 & 0.085 & 2.67E-12 & $1.34 \mathrm{E}-01$ & 20 & $\mathrm{~N}$ & G & G \\
\hline cg09557313 & 13q14.3 & 52739039 & LECT1 & rs4885947 & 52735009 & $\mathrm{C}$ & 0.037 & $1.23 \mathrm{E}-03$ & 1.46E-40 & 0.675 & 0.100 & 1.37E-11 & 1.02E-01 & 20 & $\mathrm{~N}$ & G & G \\
\hline cg09397293 & 16p13.3 & 2005032 & ZNF598 & rs72766639 & 2005819 & A & 0.174 & 1.69E-04 & $5.78 \mathrm{E}-51$ & 0.688 & 0.116 & 3.06E-09 & $2.85 \mathrm{E}-01$ & 20 & $\mathrm{~N}$ & $\mathrm{~s}$ & G \\
\hline cg26804891 & 16p13.3 & 2005241 & ZNF598 & rs11248905 & 1999727 & $\mathrm{~T}$ & 0.181 & $4.88 \mathrm{E}-05$ & 3.56E-98 & 0.539 & 0.080 & 1.62E-11 & 7.60E-02 & 20 & $\mathrm{~N}$ & $\mathrm{~s}$ & G \\
\hline cg08576185 & $16 \mathrm{p} 13.3$ & 2005683 & ZNF598 & rs72766639 & 2005819 & A & 0.174 & 1.69E-04 & 4.06E-44 & 0.740 & 0.126 & $4.76 \mathrm{E}-09$ & 3.59E-01 & 20 & $\mathrm{~N}$ & S & G \\
\hline cg10470208 & $16 \mathrm{p} 13.3$ & 2008700 & ZNF598 & rs1058474 & 1998795 & $\mathrm{~T}$ & 0.181 & 6.82E-05 & 6.56E-19 & 1.112 & 0.209 & $1.02 \mathrm{E}-07$ & 7.58E-02 & 14 & $\mathrm{~N}$ & S & G \\
\hline cg06998361 & $16 \mathrm{q} 21$ & 58110599 & C16orf80 & rs10445026 & 58109349 & G & 0.069 & $5.00 \mathrm{E}-04$ & 5.61E-97 & -0.442 & 0.069 & $1.35 \mathrm{E}-10$ & 2.53E-01 & 20 & $\mathrm{~N}$ & s & S \\
\hline
\end{tabular}

Genomic coordinates are based on Human Genome version 38 (hg38). Chr: chromosomal region (i.e., cytogenetic band); ProbePos: probe position; Gene: the gene or closest gene corresponding to the probe; SNP: top methylation quantitative trait locus (mQTL); Pos: SNP position; A1/Freq: SNP's effect allele and its frequency; $\mathrm{P}_{\mathrm{GWAS}}$ : $p$-value of the SNP in genome-wide association meta-analysis; $\mathrm{P}_{\mathrm{mQTL}}$ : $p$-value of the $\mathrm{SNP}$ in mQTLs analysis; $\mathrm{b}_{\mathrm{SMR}}, \mathrm{SE}_{\mathrm{SMR}}$, and $\mathrm{P}_{\mathrm{SMR}}$ : beta coefficient, its standard error, and $p$-value of the probe in summary

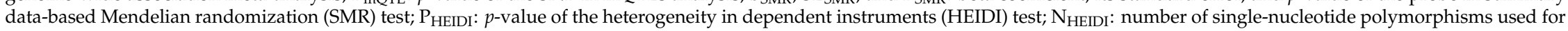
HEIDI test; Current?: whether there is any AD-associated SNP within $\pm 1 \mathrm{Mb}$ of the probe in the current genome-wide meta-analysis (N: None, G: SNP with $\mathrm{P}_{\mathrm{GWAS}}<5 \mathrm{E}-08$, and S: SNP with 5E-08 $\leq \mathrm{P}_{\mathrm{GWAS}}<5 \mathrm{E}-06$ ); Previous?: whether there is any AD-associated SNP within $\pm 1 \mathrm{Mb}$ of the probe in previous GWAS (N: None, G: SNP with $\mathrm{P}_{\mathrm{GWAS}}<5 \mathrm{E}-08$, and S: SNP with $5 \mathrm{E}-08 \leq \mathrm{P}_{\mathrm{GWAS}}<5 \mathrm{E}-06$ ); Region?: whether there is any AD-associated SNP within the chromosomal region (i.e., cytogenetic band) corresponding to the probe (N: None, G: SNP with $\mathrm{P}_{\mathrm{GWAS}}<5 \mathrm{E}-08$, and S: SNP with 5E-08 $\left.\leq \mathrm{P}_{\mathrm{GWAS}}<5 \mathrm{E}-06\right)$. 
Table 2. Brain-specific methylome-wide association results for genes that had significant probes in both brain-specific and blood-based analyses.

\begin{tabular}{|c|c|c|c|c|c|c|c|c|c|c|c|c|c|c|c|c|c|}
\hline ProbeID & Chr & ProbePos & Gene & SNP & Pos & A1 & Freq & $P_{\text {GWAS }}$ & $P_{\mathrm{mQTL}}$ & $\mathbf{b}_{\mathrm{SMR}}$ & SE & $P_{\text {SMR }}$ & $P_{\text {HEIDI }}$ & $\mathrm{N}_{\text {HEIDI }}$ & Current? & Previous? & Region? \\
\hline \multicolumn{18}{|c|}{ Plan 2: Only Males } \\
\hline $\operatorname{cg} 05206559$ & 19q13.32 & 45913997 & NANOS2 & rs66529687 & 45914171 & G & 0.867 & $1.83 \mathrm{E}-04$ & $5.86 \mathrm{E}-298$ & 0.272 & 0.043 & 2.96E-10 & 8.50E-01 & 19 & G & G & G \\
\hline \multicolumn{18}{|c|}{ Plan 3: Only Females } \\
\hline $\operatorname{cg} 04322111$ & $6 \mathrm{p} 21.32$ & 32761987 & $H L A-D Q B 2$ & rs7768538 & 32762044 & A & 0.574 & 6.15E-05 & 0 & -0.201 & 0.039 & $2.21 \mathrm{E}-07$ & $8.61 \mathrm{E}-02$ & 20 & $\mathrm{~S}$ & G & G \\
\hline cg10218546 & 6p21.32 & 32762046 & $H L A-D Q B 2$ & rs7768538 & 32762044 & A & 0.574 & 6.15E-05 & 0 & -0.198 & 0.038 & $2.18 \mathrm{E}-07$ & $8.32 \mathrm{E}-02$ & 20 & $\mathrm{~s}$ & G & G \\
\hline \multicolumn{18}{|c|}{ Plan 4: Hypertensive Subjects } \\
\hline $\operatorname{cg} 23395749$ & $5 q 35.3$ & 177557245 & FAM193B & rs1001530 & 177558514 & $\mathrm{~A}$ & 0.954 & 3.36E-04 & $2.34 \mathrm{E}-15$ & -0.791 & 0.157 & 5.17E-07 & $1.01 \mathrm{E}-01$ & 5 & $\mathrm{~N}$ & $\mathrm{~S}$ & $\mathrm{~S}$ \\
\hline \multicolumn{18}{|c|}{ Plan 5: Non-hypertensive Subjects } \\
\hline $\operatorname{cg} 08631357$ & $5 q 32$ & 150209647 & SLC6A7 & rs10076748 & 150209303 & $\mathrm{C}$ & 0.893 & 1.77E-03 & 2.82E-295 & 0.230 & 0.045 & $2.76 \mathrm{E}-07$ & $2.24 \mathrm{E}-01$ & 18 & $\mathrm{~N}$ & $\mathrm{~N}$ & G \\
\hline cg10308629 & $7 \mathrm{q} 33$ & 134670051 & $B P G M$ & rs73439998 & 134663724 & $\mathrm{C}$ & 0.979 & 3.01E-02 & $9.28 \mathrm{E}-48$ & -0.520 & 0.101 & $2.88 \mathrm{E}-07$ & $2.57 \mathrm{E}-01$ & 3 & $\mathrm{~N}$ & $\mathrm{~s}$ & $\mathrm{~s}$ \\
\hline cg24635736 & 10q26.13 & 122979534 & PSTK & rs13328826 & 122992107 & A & 0.970 & $6.26 \mathrm{E}-03$ & $2.48 \mathrm{E}-20$ & -0.374 & 0.072 & $1.68 \mathrm{E}-07$ & $8.24 \mathrm{E}-01$ & 3 & $\mathrm{~N}$ & $\mathrm{~N}$ & $\mathrm{~N}$ \\
\hline $\operatorname{cg} 15567360$ & $11 \mathrm{q} 13.4$ & 71611653 & KRTAP5-11 & rs11827208 & 71578103 & $\mathrm{C}$ & 0.980 & 1.70E-03 & $9.66 \mathrm{E}-10$ & -0.679 & 0.130 & $1.67 \mathrm{E}-07$ & $3.71 \mathrm{E}-01$ & 3 & $\mathrm{~N}$ & $\mathrm{~N}$ & $\mathrm{~s}$ \\
\hline $\operatorname{cg} 09557313$ & $13 \mathrm{q} 14.3$ & 52739039 & LECT1 & rs4885961 & 52755200 & C & 0.960 & 4.63E-03 & 6.93E-31 & 0.547 & 0.103 & $1.06 \mathrm{E}-07$ & $5.67 \mathrm{E}-01$ & 7 & $\mathrm{~N}$ & G & G \\
\hline $\operatorname{cg} 07011318$ & $16 \mathrm{p} 13.3$ & 2004943 & ZNF598 & rs72766639 & 2005819 & G & 0.826 & 1.69E-04 & 0 & 0.291 & 0.046 & 1.96E-10 & $1.12 \mathrm{E}-01$ & 17 & $\mathrm{~N}$ & S & G \\
\hline cg09397293 & 16 p13.3 & 2005032 & ZNF598 & rs72766639 & 2005819 & G & 0.826 & 1.69E-04 & 0 & 0.282 & 0.044 & 1.86E-10 & 1.13E-01 & 18 & $\mathrm{~N}$ & $\mathrm{~S}$ & G \\
\hline $\operatorname{cg} 05211189$ & 16 p13.3 & 2005402 & ZNF598 & rs11542302 & 1986934 & $\mathrm{~T}$ & 0.819 & 7.26E-05 & 0 & 0.283 & 0.043 & 7.47E-11 & $1.01 \mathrm{E}-01$ & 18 & $\mathrm{~N}$ & $\mathrm{~S}$ & G \\
\hline cg08576185 & 16 p13.3 & 2005683 & ZNF598 & rs72766639 & 2005819 & G & 0.826 & 1.69E-04 & 0 & 0.295 & 0.046 & 2.00E-10 & $9.02 \mathrm{E}-02$ & 16 & $\mathrm{~N}$ & $\mathrm{~s}$ & G \\
\hline cg06998361 & $16 q 21$ & 58110599 & C16orf80 & rs74019790 & 58107923 & $\mathrm{~T}$ & 0.931 & 5.00E-04 & $4.77 \mathrm{E}-20$ & -0.591 & 0.109 & $5.49 \mathrm{E}-08$ & $6.81 \mathrm{E}-01$ & 11 & $\mathrm{~N}$ & $\mathrm{~s}$ & $\mathrm{~S}$ \\
\hline
\end{tabular}

Genomic coordinates are based on Human Genome version 38 (hg38). Chr: chromosomal region (i.e., cytogenetic band); ProbePos: probe position; Gene: the gene or closest gene corresponding to the probe; SNP: top methylation quantitative trait locus (mQTL); Pos: SNP position; A1/Freq: SNP's effect allele and its frequency; $\mathrm{P}_{\mathrm{GWAS}}$ : $p$-value of the SNP in genome-wide association meta-analysis; $\mathrm{P}_{\mathrm{mQTL}}$ : $p$-value of the $\mathrm{SNP}$ in $\mathrm{mQTLs}$ analysis; $\mathrm{b}_{\mathrm{SMR}}, \mathrm{SE}_{\mathrm{SMR}}$, and $\mathrm{P}_{\mathrm{SMR}}$ : beta coefficient, its standard error, and $p$-value of the probe in summary data-based Mendelian randomization (SMR) test; $\mathrm{P}_{\text {HEIDI }}$ p-value of the heterogeneity in dependent instruments (HEIDI) test; $\mathrm{N}_{\mathrm{HEIDI}}$ : number of single-nucleotide polymorphisms used for HEIDI test; Current?: whether there is any AD-associated SNP within $\pm 1 \mathrm{Mb}$ of the probe in the current genome-wide meta-analysis (N: None, G: SNP with $\mathrm{P}_{\mathrm{GWAS}}<5 \mathrm{E}-08$, and S: SNP with 5E-08 $\leq \mathrm{P}_{\mathrm{GWAS}}<5 \mathrm{E}-06$ ); Previous?: whether there is any AD-associated SNP within $\pm 1 \mathrm{Mb}$ of the probe in previous GWAS (N: None, G: SNP with $\mathrm{P}_{\mathrm{GWAS}}<5 \mathrm{E}-08$, and S: SNP with 5E-08 $\leq \mathrm{P}_{\mathrm{GWAS}}<5 \mathrm{E}-06$ ); Region?: whether there is any AD-associated SNP within the chromosomal region (i.e., cytogenetic band) corresponding to the probe (N: None, G: SNP with $\mathrm{P}_{\mathrm{GWAS}}<5 \mathrm{E}-08$, and S: SNP with 5E-08 $\leq \mathrm{P}_{\mathrm{GWAS}}<5 \mathrm{E}-06$ ). 


\subsection{Group-Specific Findings}

No probes/genes outside the APOE cluster genes region (i.e., chromosome 19q13.32) were significant in both males and females (i.e., plans 2 and 3). LOC154449 (chromosome 6q27 region) was the only gene outside the APOE cluster genes region that had AD-associated probes in blood-based MWA analyses of both hypertensive and non-hypertensive subjects (i.e., plans 4 and 5).

When the $\mathrm{b}_{\mathrm{SMR}}$ of probes were compared using a Wald chi-square test, we found that 16 of 38 blood-based probes and six of eight brain-specific probes that were detected either in males or females had sex-specific effects at Bonferroni-adjusted significance levels of 0.00132 and 0.00625 , respectively (Additional File 1: Tables S3 and S4). Among 88 and 29 blood-based and brain-specific probes that were detected in either hypertensive or non-hypertensive subjects, 58 and 21 probes had significantly different effects in the two groups at Bonferroni-adjusted significance levels of 0.00057 and 0.00172 , respectively (Additional File 1: Tables S5 and S6).

\subsection{Comparison of MWA and GWAS Results}

To investigate the novelty of our findings with respect to their potential implication in AD pathogenesis, we determined whether there were AD-associated SNPs with significant $P_{\text {GWAS }}$ at genome-wide ( $\left.\mathrm{P}_{\mathrm{GWAS}}<5 \mathrm{E}-08\right)$ or suggestive $\left(5 \mathrm{E}-08 \leq \mathrm{P}_{\text {GWAS }}<5 \mathrm{E}-06\right)$ significance levels within $\pm 1 \mathrm{Mb}$ regions and/or chromosomal regions of the detected probes in our genome-wide meta-analyses or in other studies reported by GRASP [4] and NHGRI-EBI GWAS [5] catalogs.

We identified AD-associated SNPs with $\mathrm{P}_{\mathrm{GWAS}}<5 \mathrm{E}-08$ within $\pm 1 \mathrm{Mb}$ of probes corresponding to APOE, TOMM40, and NANOS2 genes (all within the chromosome 19q13.32 region) in our genome-wide meta-analyses and previous GWAS [4,5]. No SNPs with $\mathrm{P}_{\text {GWAS }}<5 \mathrm{E}-08$ were found within $\pm 1 \mathrm{Mb}$ flanking regions of any other probes in our meta-analyses. However, AD-associated SNPs with $\mathrm{P}_{\mathrm{GWAS}}<5 \mathrm{E}-08$ were previously reported by other studies within $\pm 1 \mathrm{Mb}$ of several other probes $[4,5]$. These probes were mapped to 22 genes (all outside the chromosome 19q13.32 region): CLIC1, BRD2, HLA-DPB1, ITIH2, PHLDA1 (plan 2), HLA-DQA2, HLA-DQB2, LECT1 (plan 3), and SLC25A2, PPT2-EGFL8, EGFL8, COL11A2, TREM1, NDUFA4, ZNF394, CHRNA2, ITIH2, LECT1, CMIP, NGFR, LOC100288866, MUM1, SIGLEC12, and EBF4 (plan 5).

In addition, the $\pm 1 \mathrm{Mb}$ flanking regions of several other probes attained $5 \mathrm{E}-08 \leq \mathrm{P}_{\mathrm{GWAS}}<5 \mathrm{E}-06$ in our or previous GWAS. Detailed information about these probes/genes can be found in Additional File 1: Tables $\mathrm{S} 1$ and $\mathrm{S} 2$. For instance, there were AD-associated SNPs at suggestive significance levels within $\pm 1 \mathrm{Mb}$ of probes corresponding to $A P 2 A 2, A D C Y 8, H L A-D Q A 2, H L A-D Q B 2$, and SLC35C1 (all outside the chromosome 19q13.32 region) in our GWA meta-analyses.

\subsection{Comparison of MWA and TWA Results}

Analysis of overlaps between MWA and our previous TWA results $[27,28]$ revealed that, among the potential epigenetically AD-associated genes, four genes also had significant AD-associated probes in TWA analyses (Table 3). These four genes, AIM2, DGUOK, ST14, and C16orf80, had significant probes in subjects with no history of HTN (i.e., plan 5). Of these genes, C16orf80 had significant probes in both blood-based and brain-specific MWA analyses; DGUOK and ST14 had AD-associated probes in blood-based analyses; and AIM2 had significant probes in brain-specific analyses. With respect to the TWA analyses, C16orf80 had significant probes in brain-specific analyses; AIM2, and DGUOK had significant probes in blood-based analyses; and ST14 had AD-associated probes in TWA analyses of both blood samples and brain tissue. 
Table 3. Methylome-wide association results for the four genes that had epigenetically and transcriptionally AD-associated probes.

\begin{tabular}{|c|c|c|c|c|c|c|c|c|c|c|c|c|c|c|c|c|c|}
\hline ProbeID & Chr & ProbePos & Gene & SNP & Pos & A1 & Freq & $P_{\text {GWAS }}$ & $P_{\mathrm{mQTL}}$ & $\mathbf{b}_{\text {SMR }}$ & SE $E_{\text {SMR }}$ & $P_{\text {SMR }}$ & $P_{\text {HEIDI }}$ & $\mathbf{N}_{\text {HEIDI }}$ & Current? & Previous? & Region? \\
\hline \multicolumn{18}{|c|}{ Blood-based Analyses } \\
\hline $\operatorname{cg} 03063511$ & 2p13.1 & 73930386 & DGUOK & rs6737156 & 73932607 & C & 0.036 & $5.62 \mathrm{E}-03$ & 2.71E-227 & -0.247 & 0.041 & 2.74E-09 & $1.09 \mathrm{E}-01$ & 11 & $\mathrm{~N}$ & $\mathrm{~N}$ & $\mathrm{~N}$ \\
\hline $\operatorname{cg} 02850715$ & $11 \mathrm{q} 24.3$ & 130159317 & ST14 & rs34008994 & 130165703 & $\mathrm{~T}$ & 0.096 & 1.55E-04 & $1.21 \mathrm{E}-26$ & -0.812 & 0.138 & $4.14 \mathrm{E}-09$ & 7.87E-01 & 20 & $\mathrm{~N}$ & $\mathrm{~N}$ & G \\
\hline cg21029769 & $11 \mathrm{q} 24.3$ & 130159620 & ST14 & rs34008994 & 130165703 & $\mathrm{~T}$ & 0.096 & 1.55E-04 & 4.09E-18 & -1.006 & 0.184 & $4.58 \mathrm{E}-08$ & $9.16 \mathrm{E}-01$ & 20 & $\mathrm{~N}$ & $\mathrm{~N}$ & G \\
\hline cg06998361 & $16 \mathrm{q} 21$ & 58110599 & C16orf80 & rs10445026 & 58109349 & G & 0.069 & 5.00E-04 & 5.61E-97 & -0.442 & 0.069 & $1.35 \mathrm{E}-10$ & 2.53E-01 & 20 & $\mathrm{~N}$ & S & S \\
\hline \multicolumn{18}{|c|}{ Brain-specific Analyses } \\
\hline cg11003133 & 1q23.1 & 159076601 & AIM2 & rs16841642 & 159077008 & G & 0.952 & $5.30 \mathrm{E}-03$ & $6.30 \mathrm{E}-82$ & -0.312 & 0.062 & $4.62 \mathrm{E}-07$ & 3.40E-01 & 18 & $\mathrm{~N}$ & $\mathrm{~S}$ & $\mathrm{~N}$ \\
\hline cg06998361 & $16 q 21$ & 58110599 & C16orf80 & rs74019790 & 58107923 & $\mathrm{~T}$ & 0.931 & $5.00 \mathrm{E}-04$ & 4.77E-20 & -0.591 & 0.109 & $5.49 \mathrm{E}-08$ & $6.81 \mathrm{E}-01$ & 11 & $\mathrm{~N}$ & $\mathrm{~s}$ & $\mathrm{~s}$ \\
\hline
\end{tabular}

Genomic coordinates are based on Human Genome version 38 (hg38). Chr: chromosomal region (i.e., cytogenetic band); ProbePos: probe position; Gene: the gene or closest gene
corresponding to the probe; SNP: top methylation quantitative trait locus (mQTL); Pos: SNP position; A1/Freq: SNP's effect allele and its frequency; PGWAS: -value of the SNP in genome-wide association meta-analysis; PmQTL: $p$-value of the SNP in mQTLs analysis; bSMR, SESMR, and PSMR: beta coefficient, its standard error, and $p$-value of the probe in summary data-based Mendelian randomization (SMR) test; PHEIDI: $p$-value of the heterogeneity in dependent instruments (HEIDI) test; NHEIDI: number of single-nucleotide polymorphisms used for HEIDI test; Current?: whether there is any AD-associated SNP within $\pm 1 \mathrm{Mb}$ of the probe in the current genome-wide meta-analysis (N: None, G: SNP with PGWAS < 5E-08, and S: SNP with 5E-08 < PGWAS < 5E-06); Previous?: whether there is any AD-associated SNP within $+1 \mathrm{Mb}$ of the probe in previous GWAS (N: None, G: SNP with PGWAS < 5E-08, and S: SNP with 5E-08 < PGWAS < 5E-06); Region?: whether there is any AD-associated SNP within the chromosomal region (i.e., cytogenetic band) corresponding to the probe (N: None, G: SNP with PGWAS < 5E-08, and S: SNP with 5E-08 $\leq$ PGWAS $<$ 5E-06). 


\subsection{Pathway Enrichment Analyses}

Pathway-based analyses (Tables 4 and 5) revealed that AD-associated probes/genes from blood-based MWA analyses were enriched in 16 pathways (i.e., 7, 4, 4, and 3 pathways under plans 1, 2, 3, and 5, respectively). Of these, two pathways (i.e., GABA-B receptor activation (plans 1 and 3 ) and $G A B A$ receptor activation (plans 2 and 3)) were significant in more than one plan. We also found that nine pathways (i.e., 1, 2, 2, 3, and 3 significant pathways in plans 1-5, respectively) were associated with AD when brain-specific MWA results were enriched. Of these, two pathways (MHC class II antigen presentation (plans 1 and 3) and type II diabetes mellitus (plans 2 and 4)) were significant in more than one plan and were also enriched in both brain-specific and blood-based analyses.

Table 4. Pathway-enrichment of blood-based methylome-wide association results.

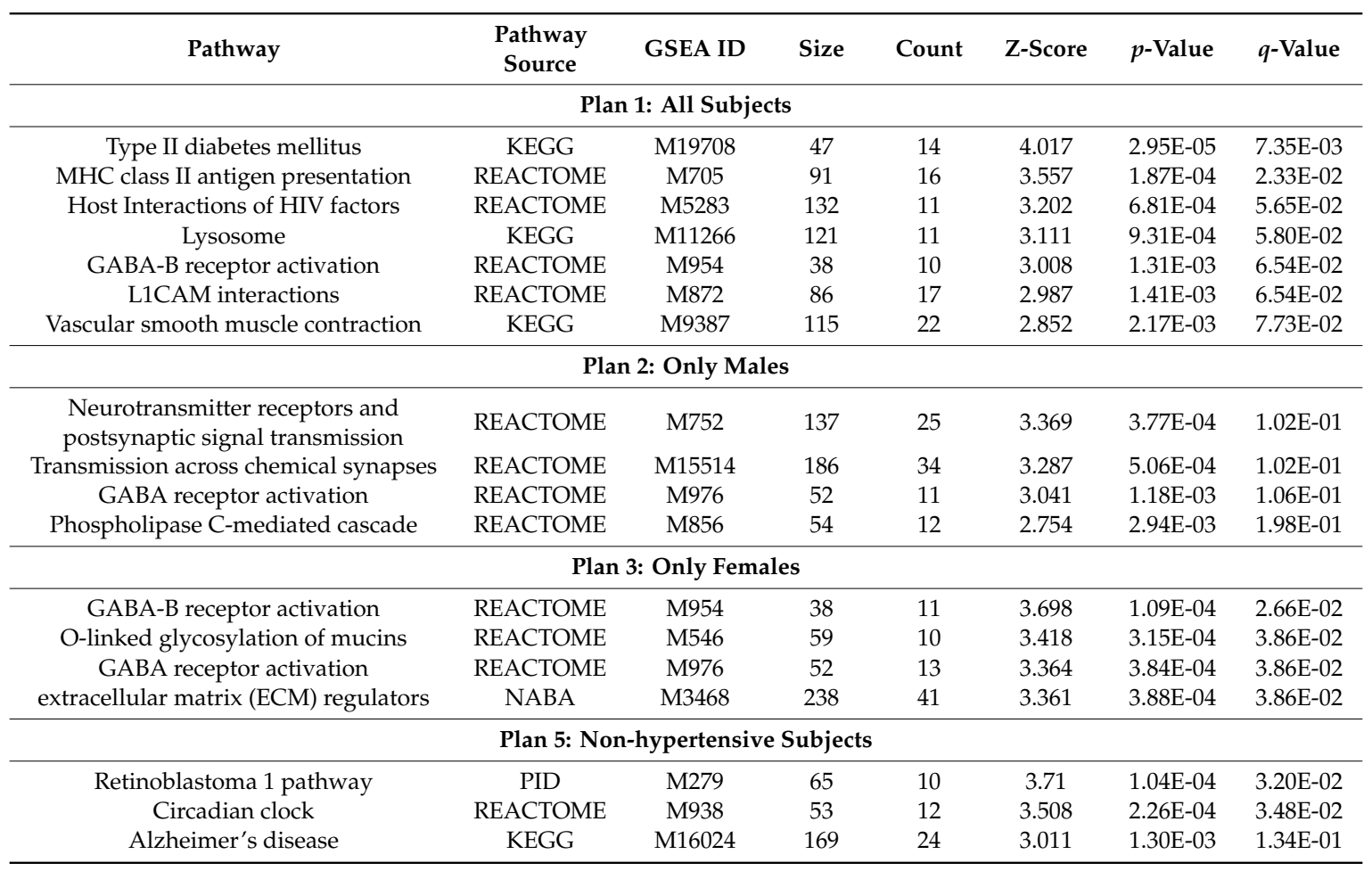

GSEA: Gene Set Enrichment Analysis; Size: number of genes in the pathway; Count: number of enriched genes in the pathway; KEGG: Kyoto Encyclopedia of Genes and Genomes; REACTOME: REACTOME pathway knowledgebase; PID: Pathway Interaction Database; NABA: Matrisome Project. The false discovery rate thresholds were 0.1, 0.2, 0.05 , and 0.15 for plans $1,2,3$, and 5 , respectively.

Table 5. Pathway-enrichment of brain-specific methylome-wide association results.

\begin{tabular}{|c|c|c|c|c|c|c|c|}
\hline Pathway & Pathway Source & GSEA ID & Size & Count & Z-Score & $p$-Value & $q$-Value \\
\hline \multicolumn{8}{|l|}{ Plan 1: All Subjects } \\
\hline MHC class II antigen presentation & REACTOME & M705 & 91 & 14 & 3.3 & $4.84 \mathrm{E}-04$ & 1.07E-01 \\
\hline \multicolumn{8}{|l|}{ Plan 2: Only Males } \\
\hline Ubiquitin mediated proteolysis & KEGG & M15247 & 138 & 14 & 3.198 & $6.91 \mathrm{E}-04$ & $1.54 \mathrm{E}-01$ \\
\hline Type II diabetes mellitus & KEGG & M19708 & 47 & 17 & 2.89 & 1.93E-03 & 2.15E-01 \\
\hline \multicolumn{8}{|l|}{ Plan 3: Only Females } \\
\hline \multirow{2}{*}{$\begin{array}{l}\text { MHC class II antigen presentation } \\
\text { Transport of inorganic cations/anions and } \\
\text { amino acids/oligopeptides }\end{array}$} & REACTOME & M705 & 91 & 18 & 3.138 & 8.50E-04 & $1.56 \mathrm{E}-01$ \\
\hline & REACTOME & M823 & 94 & 11 & 2.849 & 2.19E-03 & 2.02E-01 \\
\hline \multicolumn{8}{|l|}{ Plan 4: Hypertensive Subjects } \\
\hline DNA repair & REACTOME & M15434 & 112 & 10 & 3.87 & $5.44 \mathrm{E}-05$ & $1.26 \mathrm{E}-02$ \\
\hline Type II diabetes mellitus & KEGG & M19708 & 47 & 10 & 3.622 & $1.46 \mathrm{E}-04$ & $1.69 \mathrm{E}-02$ \\
\hline $\begin{array}{l}\text { Extracellular matrix (ECM) affiliated } \\
\text { proteins }\end{array}$ & NABA & M5880 & 171 & 22 & 3.019 & $1.27 \mathrm{E}-03$ & $9.77 \mathrm{E}-02$ \\
\hline
\end{tabular}


Table 5. Cont.

\begin{tabular}{|c|c|c|c|c|c|c|c|}
\hline Pathway & Pathway Source & GSEA ID & Size & Count & Z-Score & $p$-Value & $q$-Value \\
\hline \multicolumn{8}{|l|}{ Plan 5: Non-hypertensive Subjects } \\
\hline $\begin{array}{l}\text { Respiratory electron transport, ATP } \\
\text { synthesis by chemiosmotic coupling, and } \\
\text { heat production by uncoupling proteins }\end{array}$ & REACTOME & M1025 & 98 & 10 & 3.851 & $5.89 \mathrm{E}-05$ & $1.66 \mathrm{E}-02$ \\
\hline Hematopoietic cell lineage & KEGG & M6856 & 88 & 13 & 3.003 & $1.33 \mathrm{E}-03$ & $1.88 \mathrm{E}-01$ \\
\hline $\begin{array}{l}\text { The citric acid (TCA) cycle and respiratory } \\
\text { electron transport }\end{array}$ & REACTOME & M516 & 141 & 14 & 2.933 & $1.68 \mathrm{E}-03$ & $1.88 \mathrm{E}-01$ \\
\hline
\end{tabular}

GSEA: Gene Set Enrichment Analysis; Size: number of genes in the pathway; Count: number of enriched genes in the pathway; KEGG: Kyoto Encyclopedia of Genes and Genomes; REACTOME: REACTOME pathway knowledgebase; PID: Pathway Interaction Database; NABA: Matrisome Project. The false discovery rate thresholds were 0.2, 0.25, $0.25,0.1$, and 0.2 for plans $1-5$, respectively.

\section{Discussion}

Despite the detection of many genetic variants and identification of several non-genetic factors that may play roles in AD susceptibility, the definitive underlying mechanisms in most AD cases is unclear. Thus, epigenetic mechanisms may be key contributors to the heterogeneous nature of $\operatorname{AD}[9,10,13,23]$. The epigenetic architecture of $\mathrm{AD}$ has been widely investigated in case-control studies and cell/animal models [12]. The AD-associated epigenetic modifications found in these studies can be environmentally induced or genetically driven (i.e., through cis acting variants).

We combined the results from our previous GWAS $[27,28]$ with data from two publicly available mQTLs studies of brain tissue [30] and blood samples [29] to identify genes that might be epigenetically associated with AD. In contrast to studies using individual-level data, epigenetic associations detected by summary data-based analyses are all genetically driven [26]. A major focus of our study was to explore potential genetically driven epigenetic heterogeneity of AD based on its two main risk factors (i.e., sex [31-37] and HTN [8,38,39]). Therefore, in order to investigate sex-specific and HTN-specific epigenetic changes, our MWA analyses were performed under five alternative plans in which summary results from GWAS on either all subjects, only males, only females [27], only subjects with a history of HTN, or only subjects with no history of HTN [28] were included in analyses.

Our analyses demonstrated that 152 probes corresponding to 113 genes were epigenetically associated with AD. The top mQTLs corresponding to these probes were mostly nominally significant in our genome-wide meta-analyses. This might be in part due to suboptimal statistical power of our analyses which can be improved by analyzing larger datasets or more importantly due to the genetic heterogeneity of AD within and between the analyzed cohorts (i.e., LOADFS, CHS, FHS, and HRS). The $\pm 1 \mathrm{Mb}$ flanking regions of $\sim 18 \%$ and $\sim 34 \%$ of detected probes had attained $\mathrm{P}_{\mathrm{GWAS}}<5 \mathrm{E}-08$ and $5 \mathrm{E}-08 \leq \mathrm{P}_{\mathrm{GWAS}}<5 \mathrm{E}-06$, respectively, in our genome-wide meta-analyses or other studies reported by GWAS databases $[4,5]$. Comparing our findings with those detected in other SMR-based analyses of AD $[24,25]$ revealed that TOMM40, which had significant probes in brain-specific analyses under all five plans of our study, was epigenetically associated with AD in a previous study [24].

Investigating group-specific epigenetic alterations, we found that probes corresponding to APOE and TOMM40 genes (i.e., inside the chromosome 19q13.32 region) were significant in blood-based and brain-specific analyses, respectively, of both males and females (i.e., plans 2 and 3) and both hypertensive and non-hypertensive groups (i.e., plans 4 and 5). However, several probes (all outside the chromosome 19q13.32 region, except cg05206559 corresponding to NANOS2 gene in males) were group-specifically associated with $\mathrm{AD}$, indicating potential genetically driven epigenetic heterogeneity of AD based on the two studied risk factors. For instance, we found that among 38 and eight probes that were detected in blood-based and brain-specific analyses, respectively, in either males or females, 22 probes had sex-specific effects when their $b_{S M R}$ were compared between the two sexes using a Wald chi-square test (Additional File 1: Tables S3 and S4). Comparing results from hypertensive and non-hypertensive groups, we found that there were 88 (blood-based analyses) and 29 (brain-specific analyses) significant probes outside the $A P O E$ region which were not in common between these two 
groups. Of these, 79 probes had group-specific effects when their $b_{\mathrm{SMR}}$ were compared between hypertensive and non-hypertensive groups (Additional File 1: Tables S5 and S6). Addressing genetic and epigenetic heterogeneities of $\mathrm{AD}$ is essential for understanding its pathogenesis and developing more efficient and personalized medical interventions tailored to the genetic and epigenetic profiles of individuals.

Our MWA analyses were performed using both brain-specific and blood-based mQTLs data which provided the opportunity to assess the consistency of potential AD-associated epigenetic changes detected in these analyses. Although the pattern of DNA methylation can be tissue- or cell-specific $[6,60]$, previous studies have demonstrated the utility of blood samples for investigating AD-associated epigenetic modifications by reporting global or gene-specific methylation changes in AD subjects compared with matched healthy controls [61-65]. This might be due to the systemic sequelae of AD, as AD may extensively impact cellular and molecular processes in peripheral tissues and nonneural cells including red blood cells, leukocytes, and platelets [66-71]. In addition, blood-based analyses may provide more statistical power than brain-specific studies, which generally have smaller sample sizes due to difficulties in obtaining brain samples from living subjects. Consistent with previous reports, our findings supported the feasibility of using data from blood samples to investigate epigenetic changes involved in AD. The direction of blood-based and brain-specific effects were the same for $\sim 77 \%$ of probes and the effects of less than $1 \%$ of probes were significantly different between the two analyses across the five analysis plans of interest. We also found that probes corresponding to 10 genes were associated with AD in both blood-based and brain-speficic MWA analyses (Tables 1 and 2). Most of these genes were previously implicated in $\mathrm{AD}$ at genome-wide or suggestive significance levels by GWAS [4,5], except SLC6A7, PSTK, and KRTAP5-11. AD-associated SNPs at $\mathrm{P}_{\mathrm{GWAS}}<5 \mathrm{E}-08$ were found within $\pm 1 \mathrm{Mb}$ of probes mapped to NANOS2, HLA-DQB2, and LECT1 in our meta-analyses and/or previous GWAS. SNPs with $5 \mathrm{E}-08 \leq \mathrm{P}_{\mathrm{GWAS}}<5 \mathrm{E}-06$ were found within $\pm 1 \mathrm{Mb}$ flanking regions of probes corresponding to FAM193B, BPGM, ZNF598, and C16orf80. Moreover, empirical evidence links some of these genes to $\mathrm{AD}$ in humans and animal models (e.g., SLC6A7 [72] and BPGM [71]).

It should be stressed that the identified AD-associated genes in summary-based analyses do not prove any definitive causal relationships. Instead, they suggest a list of prioritized genes whose potential roles in $\mathrm{AD}$ pathogenesis need to be validated by further functional studies [26]. In a recent study, Hannon et al. detected overlapping mQTL and eQTL signals with functional implications for several complex diseases/traits, such as Crohn's disease, ulcerative colitis, blood lipids, height, and schizophrenia by comparing their SMR-based analyses [73]. Therefore, to further pinpoint potential targets, we compared the list of epigenetically AD-associated genes identified from MWA analyses with transcriptionally AD-associated genes identified from our previous TWA analyses $[27,28]$.

Our comparisons identified a short list of four potentially AD-associated genes that had significant probes in both MWA and TWA analyses (i.e., AIM2, DGUOK, ST14, and C16orf80 in non-hypertensive subjects with $\mathrm{P}_{\mathrm{SMR}}$ between 4.62E-07 and 1.35E-10 in MWA analyses and between 2.18E-05 and 7.78E-07 in TWA analyses [28]). Probes corresponding to all genes but AIM2 had group-specific effects when their $\mathrm{b}_{\mathrm{SMR}}$ were compared between hypertensive and non-hypertensive groups using a Wald chi-square test (Additional File 1: Tables S5 and S6). AD-associated SNPs with $\mathrm{P}_{\mathrm{GWAS}}<5 \mathrm{E}-08$ were not found within $\pm 1 \mathrm{Mb}$ flanking regions of these probes in our meta-analyses or other studies in GWAS databases [4,5], although several SNPs with 5E-08 $\leq \mathrm{P}_{\mathrm{GWAS}}<5 \mathrm{E}-06$ were previously reported within $\pm 1 \mathrm{Mb}$ of probes corresponding to AIM2 [74] and C16orf80 [75,76]. In addition, chromosomal regions corresponding to ST14 [77] (i.e., 11q24.3 region) contained previously reported AD-associated SNPs at $\mathrm{P}<5 \mathrm{E}-08$.

A review of the literature provided additional insights, strengthening the potential roles of these four genes in AD. For instance, AIM2 encodes a protein involved in regulating cell proliferation and innate immunity [78]. SNPs mapped to this gene were previously associated with white blood cells count at $\mathrm{P}_{\mathrm{GWAS}}<5 \mathrm{E}-08$ [79]. AIM2, along with several other proteins, were suggested to initiate inflammasome formation in response to stimuli such as viruses, bacteria, and damaged cells. 
Inflammasomes mediate the release of pro-inflammatory cytokines, such as $I L-1 \beta$ and $I L-18$, that are believed to be involved in AD development [80-82]. IL-1 $\beta$ may increase in the blood, cerebrospinal fluid, and brain of AD patients and blood level of $I L-18$ may increase in early stages of AD. $I L-1 \beta$ can activate astrocytes and microglia cells and stimulate the release of APP and amyloid- $\beta(A \beta)$ from neurons. Also, $I L-18$, which is overexpressed in astrocytes, microglia, and neurons around $A \beta$ plaques, may promote $A \beta$ formation and mediate tau protein hyper-phosphorylation [82]. It was reported that methylene blue (MB), an inhibitor of inflammasome proteins such as AIM2, NLRP3, and NLRC4 [80], can decelerate the production of $A \beta$ plaques and neurofibrillary tangles. Thus, MB-based medications were suggested as potential treatments for AD [83]. Moreover, Wu et al. reported that AIM2 knock-out mice exhibited behavioral changes and impaired auditory fear memory [84].

DGUOK encodes a mitochondrial enzyme involved in the purine metabolism pathway [78]. Mutations in this gene were linked to some mitochondrial disorders with Mendelian inheritance, such as mitochondrial depletion syndrome [85]. Mitochondrial dysfunction has also been reported as an important finding in neurons of AD patients [86,87]. Ansoleaga et al. showed that DGUOK was downregulated in the precuneus and entorhinal cortex of patients in AD stages III-IV and V-VI (Braak and Braak staging system [88]), respectively, compared with matched healthy controls [89]. In addition, SNPs mapped to DGUOK were associated with systemic lupus erythematosus at $\mathrm{P}_{\mathrm{GWAS}}<$ 5E-08 [90]. The risks of developing AD and vascular dementia slightly increases among patients with autoimmune disorders, such as lupus erythematosus [91].

ST14 encodes a membrane serine protease with tumor suppressor activity [78] that was not associated with $\mathrm{AD}$ or its risk factors at $\mathrm{P}_{\mathrm{GWAS}}<5 \mathrm{E}-06$ by previous GWAS [4,5]. However, Wirz et al. found that the ortholog of ST14 is overexpressed (i.e., 5.39-fold change with $p<0.008$ ) in the frontal cortex of APPswe/PS1dE9 transgenic mice harboring mutant forms of APP and PSEN1 in response to $A \beta$ plaque development [92]. Yin et al. reported that the mouse ortholog of ST14 was upregulated in $A \beta$ plaque-associated microglia cells in $5 X F A D$ transgenic mice harboring mutant forms of $A P P$ and PSEN1 genes compared with aged-matched control mice [93].

C16orf80 (also known as BUG22 and CFAP20) encodes a highly conserved protein involved in the post-translational modification of Tubulin subunits of microtubules. Such modifications might be essential for microtubule function and stability in ciliated cells, such as sperm, and in neurons [94]. Microtubules are major component of neuronal transport machinery, in which defects can lead to neurodegenerative diseases (e.g., the role of microtubule-associated proteins, such as tau protein, in AD) $[95,96]$. In a previous study, Mendes Maia et al. reported that Drosophila melanogaster carrying mutant copies of the ortholog of C16orf80 had a short lifespan and defects in body morphology, climbing activity, and locomotion, which were mostly reversed when gene expression was restored in the nervous system [94]. However, C16orf80 was not previously associated with AD or its risk factors at $\mathrm{P}_{\text {GWAS }}<5 \mathrm{E}-06[4,5]$.

Our pathway enrichment analyses of the brain-specific and blood-based MWA results revealed that nine and 16 pathways were associated with $\mathrm{AD}$, respectively. These pathways were mostly involved in biological processes such as immune system responses (e.g., MHC class II antigen presentation), mitochondrial function (e.g., TCA cycle and respiratory electron transport), neurogenesis, synaptic function, and neurotransmitter signaling (e.g., L1CAM interactions, GABA receptor activation, neurotransmitter receptors and postsynaptic signal transmission, and transmission across chemical synapses pathways) that have been implicated in AD pathogenesis [87,97-103]. Two enriched pathways (i.e., MHC class II antigen presentation and type II diabetes mellitus) were common between the brain-speficic and blood-based MWA analyses, highlighting potential links between AD and immune system responses [102,103] and type II diabetes mellitus as an important vascular risk factor for AD [104].

Despite its rigor, we acknowledge that this study has limitations that could be addressed by future research using different methodologies and data. Using summary results from GWAS with larger sample sizes is likely to increase the statistical power of analyses. However, it should be noted that 
increasing sample sizes may not necessarily result in considerably increased power of GWAS due to the genetic heterogeneity underlying complex diseases. As mentioned above, the summary-based methylome-/transcriptome-wide approaches cannot draw definitive causal relationships between the disease of interest and detected genes [26]. Such analyses can only help generate hypotheses regarding the possible involvement of a short list of genes in the pathogenesis of the studied disorder, which need to be validated empirically. Analyzing individual-level data which provide gene expressions and epigenetic profiles for the same case and control subjects would help obtaining a more definitive view of the underlying biological processes of $\mathrm{AD}$ and, in addition, may allow investigating the roles of non-genetic factors (e.g., smoking, medications that interfere with DNA methylation, exposure to metals, nutritional ingredients) in the observed transcriptome and epigenome changes. This is particularly important because epigenetic alterations can be environmentally induced [6,9]. It would also be interesting to investigate whether detected epigenome changes are associated with AD progression. This requires data from different AD stages [88] with sufficient sample sizes. The CHS, FHS, HRS, and LOADFS datasets analyzed in our study do not provide disease staging information for AD subjects. Finally, investigating cell-specific (i.e., neurons and different glial cells) epigenetic alterations may provide valuable additional insights into the epigenetic architecture of $\mathrm{AD}$, although small sample sizes and insufficient statistical power can be a major problem for such studies.

\section{Conclusions}

Our MWA analyses revealed associations between AD and probes corresponding to 113 genes. Most of these genes were not associated with $\mathrm{AD}$ in previous GWAS and the $\pm 1 \mathrm{Mb}$ flanking regions of $\sim 45 \%$ of detected probes did not attain $P_{\mathrm{GWAS}}<5 \mathrm{E}-06$ previously. The top mQTLs corresponding to these probes were mostly nominally significant in our GWAS which might be due to suboptimal sample sizes and statistical power of our analyses and/or the genetic heterogeneity of AD within and between the analyzed cohorts. Performing MWA analyses under five plans provided the opportunity to explore potential genetically driven epigenetic heterogeneity of $\mathrm{AD}$ in contrasting groups of subjects based on their sex and history of HTN. Comparing the MWA results from plans 2 and 3 (i.e., males vs. females) and from plans 4 and 5 (i.e., hypertensive vs. non-hypertensive subjects), we found that 22 and 79 probes were group-specifically associated with $\mathrm{AD}$, respectively. Thus, this study suggests a role for genetically driven epigenetic modifications as contributing factors to the heterogeneous nature of $\mathrm{AD}$, addressing of which may have translational impacts for implementing more efficient and personalized medical interventions (e.g., developing sex-specific therapeutic targets). The potential AD-genes associations detected here do not imply casualty and should only be used as a short list to prioritize candidate genes for future studies. The comparison of MWA and TWA results together with additional information from empirical studies strengthened the possible roles of four genes (i.e., AIM2, C16orf80, DGUOK, and ST14) in AD pathogenesis and helped further prioritize the list of potentially AD-associated genes for follow-up studies. Consistent with previous reports, our findings demonstrated the applicability of blood-based mQTLs data for the study of epigenetics mechanisms of $\mathrm{AD}$ as several genes and pathways were associated with $\mathrm{AD}$ in both brain-specific and blood-based MWA analyses and the probe effects detected in these analyses did not show significant differences.

Supplementary Materials: The following are available online at http://www.mdpi.com/2077-0383/9/5/1489/s1, Additional File 1 containing Supporting Acknowledgment, Table S1: Blood-based methylome-wide association results; Table S2: Brain-specific methylome-wide association results; Table S3: Wald chi-square test to compare probes effects between males and females for probes that were significant in blood-based analyses of only one of the two groups; Table S4: Wald chi-square test to compare probes effects between males and females for probes that were significant in brain-specific analyses of only one of the two groups; Table S5: Wald chi-square test to compare probes effects between hypertensive and non-hypertensive subjects for probes that were significant in blood-based analyses of only one of the two groups; Table S6: Wald chi-square test to compare probes effects between hypertensive and non-hypertensive subjects for probes that were significant in brain-specific analyses of only one of the two groups. 
Author Contributions: The authors' responsibilities were as follows: A.N. and A.M.K. designed the study, A.N. analyzed data, A.M.K. and A.I.Y. provided critical feedback, A.N., A.M.K. and A.I.Y. wrote the manuscript. All authors have read and agreed to the published version of the manuscript.

Funding: This research was funded by grants from the National Institute on Aging (P01AG043352, R01AG047310, and R01AG065477). The funders had no role in study design, data collection and analysis, decision to publish, or manuscript preparation. The content is solely the responsibility of the authors and does not necessarily represent the official views of the National Institutes of Health.

Acknowledgments: Please see the Supporting Acknowledgment in Additional File 1 regarding the CHS, FHS, HRS, and LOADFS datasets used for genome-wide association meta-analyses.

Conflicts of Interest: The authors declare no competing interests.

\section{Abbreviations}

\begin{tabular}{|c|c|}
\hline$A B C A 7$ & ATP Binding Cassette Subfamily A Member 7 \\
\hline $\mathrm{AD}$ & Alzheimer's Disease \\
\hline$A D C Y 8$ & Adenylate Cyclase 8 \\
\hline AIM2 & Absent in Melanoma 2 \\
\hline ANK1 & Ankyrin 1 \\
\hline$A P 2 A 2$ & Adaptor Related Protein Complex 2 Subunit Alpha 2 \\
\hline APOC1 & Apolipoprotein C1 \\
\hline$A P O E$ & Apolipoprotein E \\
\hline$A P P$ & Amyloid Beta Precursor Protein \\
\hline$A \beta$ & Amyloid- $\beta$ \\
\hline BIN1 & Bridging Integrator 1 \\
\hline$B P G M$ & Bisphosphoglycerate Mutase \\
\hline BRD2 & Bromodomain Containing 2 \\
\hline BUG22 & Basal Body Upregulated Gene 22 \\
\hline C10orf54 & Chromosome 10 Open Reading Frame 54 \\
\hline C16orf80 & Chromosome 16 Open Reading Frame 80 \\
\hline $\mathrm{CDH} 23$ & Cadherin Related 23 \\
\hline CFAP20 & Cilia and Flagella Associated Protein 20 \\
\hline CHRNA2 & Cholinergic Receptor Nicotinic Alpha 2 Subunit \\
\hline $\mathrm{CHS}$ & Cardiovascular Health Study \\
\hline CLIC1 & Chloride Intracellular Channel 1 \\
\hline CLU & Clusterin \\
\hline CMIP & C-Maf Inducing Protein \\
\hline COL11A2 & Collagen Type XI Alpha 2 Chain \\
\hline $\mathrm{dbGaP}$ & The Database of Genotypes and Phenotypes \\
\hline DGUOK & Deoxyguanosine Kinase \\
\hline DUSP22 & Dual Specificity Phosphatase 22 \\
\hline EBF4 & Early B Cell Factor Family Member 4 \\
\hline EGFL8 & Epidermal Growth Factor-Like Like Domain Multiple 8 \\
\hline eQTL & Expression Quantitative trait Locus \\
\hline FAM193B & Family with Sequence Similarity 193 Member B \\
\hline FDR & False Discovery Rate \\
\hline FHS & Framingham Heart Study \\
\hline GABA & Gamma-Aminobutyric Acid \\
\hline GRASP & Genome-Wide Repository of Associations Between SNPs and Phenotypes \\
\hline GSA & Gene Set Analysis \\
\hline GSA-SNP2 & Gene Set Analysis-Single-Nucleotide-Polymorphism-2 \\
\hline GSEA & Gene Set Enrichment Analysis \\
\hline GWAS & Genome-Wide Association Study \\
\hline HEIDI & Heterogeneity in Dependent Instruments \\
\hline$H L A-D P B 1$ & Human Leukocyte Antigen Class II, DP Beta 1 \\
\hline$H L A-D Q A 2$ & Human Leukocyte Antigen Class II, DQ Alpha 2 \\
\hline
\end{tabular}


HLA-DQB2 Human Leukocyte Antigen Class II, DQ Beta 2

HLA-DRB1 Human Leukocyte Antigen Class II, DR Beta 1

HLA-DRB5 Human Leukocyte Antigen Class II, DR Beta 5

HRS

HTN

ICD-9

IGR

IL-18

$I L-1 \beta$

IRB

Health and Retirement Study

Hypertension

International Classification of Disease codes, Ninth revision

Inter-Genic Region

Interleukin 18

ITIH2

Interleukin 1 Beta

KEGG

Institutional Review Board

KRTAP5-11

Inter-Alpha-Trypsin Inhibitor Heavy Chain 2

L1CAM

LECT1

Kyoto Encyclopedia of Genes and Genomes

LOADFS

LOC100288866

Keratin Associated Protein 5-11

L1 Cell Adhesion Molecule

Leukocyte Cell Derived Chemotaxin 1

LOC154449

Late-Onset Alzheimer's Disease Family Study

Uncharacterized LOC100288866

MAPT

Uncharacterized LOC154449

$\mathrm{MB}$

Microtubule Associated Protein Tau

MHC

Methylene Blue

mQTL

Major Histocompatibility Complex

MUM1

Methylation Quantitative trait Locus

MWA

Melanoma Ubiquitous Mutated Protein 1

NABA

Methylome-Wide Association

NANOS2

Matrisome Project

NDUFA4

Nanos C2HC-Type Zinc Finger 2

NGFR Nerve Growth Factor Receptor

NHGRI-EBI GWAS

National Human Genome Research Institute-European Bioinformatics Institute Genome-Wide Association Studies Catalog

NINCDS-ADRDA

National Institute of Neurological and Communicative Disorders and Stroke of the United States-the Alzheimer's Disease and Related Disorders Association

NLRC4

Nucleotide-Binding Oligomerization Domain, Leucine Rich Repeat and Caspase

Recruitment Domain Containing 4

NLRP3

Nucleotide-Binding Oligomerization Domain, Leucine Rich Repeat and Pyrin

Domain Containing 3

PID

Pleckstrin Homology Like Domain Family A Member 1

Pathway Interaction Database

PPT2-EGFL8

Palmitoyl-Protein Thioesterase 2-Epidermal Growth Factor-Like Like Domain

PSEN1

Multiple 8 Readthrough

PSTK

RHBDF2

RPL13

SIGLEC12

SLC24A4

SLC25A2

SLC35C1

SLC6A7

SMR

SNP

SORBS3

SORL1

Presenilin 1

Phosphoseryl-TRNA Kinase

Rhomboid 5 Homolog 2

Ribosomal Protein L13

Sialic Acid Binding Immunoglobulin Like Lectin 12

Solute Carrier Family 24 Member 4

Solute Carrier Family 25 Member 2

Solute Carrier Family 35 Member C1

Solute Carrier Family 6 Member 7

Summary Data-Based Mendelian Randomization

Single-Nucleotide Polymorphism

Sorbin And SH3 Domain Containing 3

Sortilin Related Receptor 1 


$\begin{array}{ll}\text { ST14 } & \text { Suppression of Tumorigenicity 14 } \\ \text { TCA } & \text { Tricarboxylic Acid } \\ \text { TOMM40 } & \text { Translocase of Outer Mitochondrial Membrane 40 } \\ \text { TREM1 } & \text { Triggering Receptor Expressed on Myeloid Cells 1 } \\ \text { TWA } & \text { Transcriptome-Wide Association } \\ \text { ZNF394 } & \text { Zinc Finger Protein 394 } \\ \text { ZNF598 } & \text { Zinc Finger Protein 598 }\end{array}$

\section{References}

1. Alzheimer's Association. 2016 Alzheimer's disease facts and figures. Alzheimers Dement. 2016, 12, 459-509. [CrossRef] [PubMed]

2. Ridge, P.G.; Hoyt, K.B.; Boehme, K.; Mukherjee, S.; Crane, P.K.; Haines, J.L.; Mayeux, R.; Farrer, L.A.; Pericak-Vance, M.A.; Schellenberg, G.D.; et al. Assessment of the genetic variance of late-onset Alzheimer's disease. Neurobiol. Aging 2016, 41, 200.e13-200.e20. [CrossRef] [PubMed]

3. Raghavan, N.; Tosto, G. Genetics of Alzheimer's disease: The importance of polygenic and epistatic components. Curr. Neurol. Neurosci. Rep. 2017, 17, 78. [CrossRef] [PubMed]

4. Leslie, R.; O'Donnell, C.J.; Johnson, A.D. GRASP: Analysis of genotype-phenotype results from 1390 genome-wide association studies and corresponding open access database. Bioinformatics 2014, 30, i185-i194. [CrossRef] [PubMed]

5. MacArthur, J.; Bowler, E.; Cerezo, M.; Gil, L.; Hall, P.; Hastings, E.; Junkins, H.; McMahon, A.; Milano, A.; Morales, J.; et al. The new NHGRI-EBI Catalog of published genome-wide association studies (GWAS Catalog). Nucleic Acids Res. 2017, 45, D896-D901. [CrossRef]

6. Sanchez-Mut, J.V.; Gräff, J. Epigenetic alterations in Alzheimer's disease. Front. Behav. Neurosci. 2015, 9, 347. [CrossRef]

7. Daviglus, M.L.; Bell, C.C.; Berrettini, W.; Bowen, P.E.; Connolly, E.S.; Cox, N.J.; Dunbar-Jacob, J.M.; Granieri, E.C.; Hunt, G.; McGarry, K.; et al. NIH state-of-the-science conference statement: Preventing Alzheimer's disease and cognitive decline. NIH Consens. State Sci. Statements 2010, 27, 1-30.

8. Power, M.C.; Weuve, J.; Gagne, J.J.; McQueen, M.B.; Viswanathan, A.; Blacker, D. The association between blood pressure and incident Alzheimer disease: A systematic review and meta-analysis. Epidemiology 2011, 22, 646-659. [CrossRef] [PubMed]

9. Lahiri, D.K.; Zawia, N.H.; Greig, N.H.; Sambamurti, K.; Maloney, B. Early-life events may trigger biochemical pathways for Alzheimer's disease: The “LEARn” model. Biogerontology 2008, 9, 375-379. [CrossRef] [PubMed]

10. Yokoyama, A.S.; Rutledge, J.C.; Medici, V. DNA methylation alterations in Alzheimer's disease. Environ. Epigenet. 2017, 3, dvx008. [CrossRef]

11. Sanchez-Mut, J.V.; Aso, E.; Panayotis, N.; Lott, I.; Dierssen, M.; Rabano, A.; Urdinguio, R.G.; Fernandez, A.F.; Astudillo, A.; Martin-Subero, J.I.; et al. DNA methylation map of mouse and human brain identifies target genes in Alzheimer's disease. Brain 2013, 136, 3018-3027. [CrossRef] [PubMed]

12. Wen, K.-X.; Miliç, J.; El-Khodor, B.; Dhana, K.; Nano, J.; Pulido, T.; Kraja, B.; Zaciragic, A.; Bramer, W.M.; Troup, J.; et al. The role of DNA methylation and histone modifications in neurodegenerative diseases: A systematic review. PLoS ONE 2016, 11, e0167201. [CrossRef]

13. Liu, X.; Jiao, B.; Shen, L. The epigenetics of Alzheimer's disease: Factors and therapeutic implications. Front. Genet. 2018, 9, 579. [CrossRef] [PubMed]

14. Iwata, A.; Nagata, K.; Hatsuta, H.; Takuma, H.; Bundo, M.; Iwamoto, K.; Tamaoka, A.; Murayama, S.; Saido, T.; Tsuji, S. Altered CpG methylation in sporadic Alzheimer's disease is associated with APP and MAPT dysregulation. Hum. Mol. Genet. 2014, 23, 648-656. [CrossRef] [PubMed]

15. Foraker, J.; Millard, S.P.; Leong, L.; Thomson, Z.; Chen, S.; Keene, C.D.; Bekris, L.M.; Yu, C.-E. The APOE gene is differentially methylated in Alzheimer's disease. J. Alzheimers Dis. 2015, 48, 745-755. [CrossRef] [PubMed]

16. De Jager, P.L.; Srivastava, G.; Lunnon, K.; Burgess, J.; Schalkwyk, L.C.; Yu, L.; Eaton, M.L.; Keenan, B.T.; Ernst, J.; McCabe, C.; et al. Alzheimer's disease: Early alterations in brain DNA methylation at ANK1, BIN1, RHBDF2 and other loci. Nat. Neurosci. 2014, 17, 1156-1163. [CrossRef] [PubMed] 
17. Lunnon, K.; Smith, R.; Hannon, E.; De Jager, P.L.; Srivastava, G.; Volta, M.; Troakes, C.; Al-Sarraj, S.; Burrage, J.; Macdonald, R.; et al. Methylomic profiling implicates cortical deregulation of ANK1 in Alzheimer's disease. Nat. Neurosci. 2014, 17, 1164-1170. [CrossRef]

18. Semick, S.A.; Bharadwaj, R.A.; Collado-Torres, L.; Tao, R.; Shin, J.H.; Deep-Soboslay, A.; Weiss, J.R.; Weinberger, D.R.; Hyde, T.M.; Kleinman, J.E.; et al. Integrated DNA methylation and gene expression profiling across multiple brain regions implicate novel genes in Alzheimer's disease. Acta Neuropathol. 2019, 137, 557-569. [CrossRef]

19. Sanchez-Mut, J.V.; Aso, E.; Heyn, H.; Matsuda, T.; Bock, C.; Ferrer, I.; Esteller, M. Promoter hypermethylation of the phosphatase DUSP22 mediates PKA-dependent TAU phosphorylation and CREB activation in Alzheimer's disease. Hippocampus 2014, 24, 363-368. [CrossRef]

20. Siegmund, K.D.; Connor, C.M.; Campan, M.; Long, T.I.; Weisenberger, D.J.; Biniszkiewicz, D.; Jaenisch, R.; Laird, P.W.; Akbarian, S. DNA methylation in the human cerebral cortex is dynamically regulated throughout the life span and involves differentiated neurons. PLoS ONE 2007, 2, e895. [CrossRef]

21. Lord, J.; Cruchaga, C. The epigenetic landscape of Alzheimer's disease. Nat. Neurosci. 2014, 17, 1138-1140. [CrossRef] [PubMed]

22. Yu, L.; Chibnik, L.B.; Srivastava, G.P.; Pochet, N.; Yang, J.; Xu, J.; Kozubek, J.; Obholzer, N.; Leurgans, S.E.; Schneider, J.A.; et al. Association of Brain DNA methylation in SORL1, ABCA7, HLA-DRB5, SLC24A4, and BIN1 with pathological diagnosis of Alzheimer disease. JAMA Neurol. 2015, 72, 15-24. [CrossRef] [PubMed]

23. Fetahu, I.S.; Ma, D.; Rabidou, K.; Argueta, C.; Smith, M.; Liu, H.; Wu, F.; Shi, Y.G. Epigenetic signatures of methylated DNA cytosine in Alzheimer's disease. Sci. Adv. 2019, 5, eaaw2880. [CrossRef] [PubMed]

24. Marioni, R.E.; Harris, S.E.; Zhang, Q.; McRae, A.F.; Hagenaars, S.P.; Hill, W.D.; Davies, G.; Ritchie, C.W.; Gale, C.R.; Starr, J.M.; et al. GWAS on family history of Alzheimer's disease. Transl. Psychiatry 2018, 8, 99. [CrossRef] [PubMed]

25. Zhao, T.; Hu, Y.; Zang, T.; Wang, Y. Integrate GWAS, eQTL, and mQTL data to identify Alzheimer's disease-related genes. Front. Genet. 2019, 10, 1021. [CrossRef]

26. Zhu, Z.; Zhang, F.; Hu, H.; Bakshi, A.; Robinson, M.R.; Powell, J.E.; Montgomery, G.W.; Goddard, M.E.; Wray, N.R.; Visscher, P.M.; et al. Integration of summary data from GWAS and eQTL studies predicts complex trait gene targets. Nat. Genet. 2016, 48, 481-487. [CrossRef]

27. Nazarian, A.; Yashin, A.I.; Kulminski, A.M. Genome-wide analysis of genetic predisposition to Alzheimer's disease and related sex disparities. Alzheimers Res. Ther. 2019, 11, 5. [CrossRef]

28. Nazarian, A.; Arbeev, K.G.; Yashkin, A.P.; Kulminski, A.M. Genetic heterogeneity of Alzheimer's disease in subjects with and without hypertension. GeroScience 2019, 41, 137-154. [CrossRef]

29. McRae, A.F.; Marioni, R.E.; Shah, S.; Yang, J.; Powell, J.E.; Harris, S.E.; Gibson, J.; Henders, A.K.; Bowdler, L.; Painter, J.N.; et al. Identification of 55,000 Replicated DNA Methylation QTL. Sci. Rep. 2018, 8, 17605. [CrossRef]

30. Qi, T.; Wu, Y.; Zeng, J.; Zhang, F.; Xue, A.; Jiang, L.; Zhu, Z.; Kemper, K.; Yengo, L.; Zheng, Z.; et al. Identifying gene targets for brain-related traits using transcriptomic and methylomic data from blood. Nat. Commun. 2018, 9, 2282. [CrossRef]

31. Genin, E.; Hannequin, D.; Wallon, D.; Sleegers, K.; Hiltunen, M.; Combarros, O.; Bullido, M.J.; Engelborghs, S.; De Deyn, P.; Berr, C.; et al. APOE and Alzheimer disease: A major gene with semi-dominant inheritance. Mol. Psychiatry 2011, 16, 903-907. [CrossRef] [PubMed]

32. Andersen, K.; Launer, L.J.; Dewey, M.E.; Letenneur, L.; Ott, A.; Copeland, J.R.; Dartigues, J.F.; Kragh-Sorensen, P.; Baldereschi, M.; Brayne, C.; et al. Gender differences in the incidence of AD and vascular dementia: The EURODEM Studies. EURODEM incidence research group. Neurology 1999, 53, 1992-1997. [CrossRef] [PubMed]

33. Carter, C.L.; Resnick, E.M.; Mallampalli, M.; Kalbarczyk, A. Sex and gender differences in Alzheimer's disease: Recommendations for future research. J. Womens Health (Larchmt.) 2012, 21, 1018-1023. [CrossRef] [PubMed]

34. Mayeux, R. Epidemiology of neurodegeneration. Annu. Rev. Neurosci. 2003, 26, 81-104. [CrossRef]

35. Mielke, M.M.; Vemuri, P.; Rocca, W.A. Clinical epidemiology of Alzheimer's disease: Assessing sex and gender differences. Clin. Epidemiol. 2014, 6, 37-48. [CrossRef]

36. Henderson, V.W.; Buckwalter, J.G. Cognitive deficits of men and women with Alzheimer's disease. Neurology 1994, 44, 90-96. [CrossRef] 
37. Barnes, L.L.; Wilson, R.S.; Bienias, J.L.; Schneider, J.A.; Evans, D.A.; Bennett, D.A. Sex differences in the clinical manifestations of Alzheimer disease pathology. Arch. Gen. Psychiatry 2005, 62, 685-691. [CrossRef]

38. Faraco, G.; Iadecola, C. Hypertension: A harbinger of stroke and dementia. Hypertension 2013, 62, 810-817. [CrossRef]

39. Csiszar, A.; Tarantini, S.; Fülöp, G.A.; Kiss, T.; Valcarcel-Ares, M.N.; Galvan, V.; Ungvari, Z.; Yabluchanskiy, A. Hypertension impairs neurovascular coupling and promotes microvascular injury: Role in exacerbation of Alzheimer's disease. GeroScience 2017, 39, 359-372. [CrossRef]

40. Lloyd-Jones, L.R.; Holloway, A.; McRae, A.; Yang, J.; Small, K.; Zhao, J.; Zeng, B.; Bakshi, A.; Metspalu, A.; Dermitzakis, M.; et al. The genetic architecture of gene expression in peripheral blood. Am. J. Hum. Genet. 2017, 100, 228-237. [CrossRef]

41. GTEx Consortium Genetic effects on gene expression across human tissues. Nature 2017, 550, $204-213$. [CrossRef] [PubMed]

42. Fried, L.P.; Borhani, N.O.; Enright, P.; Furberg, C.D.; Gardin, J.M.; Kronmal, R.A.; Kuller, L.H.; Manolio, T.A.; Mittelmark, M.B.; Newman, A. The cardiovascular health study: Design and rationale. Ann. Epidemiol. 1991, 1, 263-276. [CrossRef]

43. Dawber, T.R.; Meadors, G.F.; Moore, F.E. Epidemiological approaches to heart disease: The Framingham study. Am. J. Public Health Nations Health 1951, 41, 279-286. [CrossRef] [PubMed]

44. Feinleib, M.; Kannel, W.B.; Garrison, R.J.; McNamara, P.M.; Castelli, W.P. The Framingham offspring study: Design and preliminary data. Prev. Med. 1975, 4, 518-525. [CrossRef]

45. Lee, J.H.; Cheng, R.; Graff-Radford, N.; Foroud, T.; Mayeux, R. Analyses of the national institute on aging late-onset Alzheimer's disease family study: Implication of additional loci. Arch. Neurol. 2008, 65, 1518-1526. [CrossRef]

46. Sonnega, A.; Faul, J.D.; Ofstedal, M.B.; Langa, K.M.; Phillips, J.W.; Weir, D.R. Cohort profile: The health and retirement study (HRS). Int. J. Epidemiol. 2014, 43, 576-585. [CrossRef]

47. McKhann, G.; Drachman, D.; Folstein, M.; Katzman, R.; Price, D.; Stadlan, E.M. Clinical diagnosis of Alzheimer's disease: Report of the NINCDS-ADRDA Work Group under the auspices of Department of Health and Human Services Task Force on Alzheimer's Disease. Neurology 1984, 34, 939-944. [CrossRef]

48. Purcell, S.; Neale, B.; Todd-Brown, K.; Thomas, L.; Ferreira, M.A.R.; Bender, D.; Maller, J.; Sklar, P.; de Bakker, P.I.W.; Daly, M.J.; et al. PLINK: A tool set for whole-genome association and population-based linkage analyses. Am. J. Hum. Genet. 2007, 81, 559-575. [CrossRef]

49. Bates, D.; Mächler, M.; Bolker, B.; Walker, S. Fitting linear mixed-effects models using lme4. J. Stat. Softw. 2015, 67, 1-48. [CrossRef]

50. Mägi, R.; Morris, A.P. GWAMA: Software for genome-wide association meta-analysis. BMC Bioinform. 2010, 11, 288. [CrossRef]

51. Allison, P.D. Comparing logit and probit coefficients across groups. Sociol. Methods Res. 1999, 28, 186-208. [CrossRef]

52. Hannon, E.; Gorrie-Stone, T.J.; Smart, M.C.; Burrage, J.; Hughes, A.; Bao, Y.; Kumari, M.; Schalkwyk, L.C.; Mill, J. Leveraging DNA-methylation quantitative-trait loci to characterize the relationship between methylomic variation, gene expression, and complex traits. Am. J. Hum. Genet. 2018, 103, 654-665. [CrossRef] [PubMed]

53. Yoon, S.; Nguyen, H.C.T.; Yoo, Y.J.; Kim, J.; Baik, B.; Kim, S.; Kim, J.; Kim, S.; Nam, D. Efficient pathway enrichment and network analysis of GWAS summary data using GSA-SNP2. Nucleic Acids Res. 2018, 46 , e60. [CrossRef]

54. Subramanian, A.; Tamayo, P.; Mootha, V.K.; Mukherjee, S.; Ebert, B.L.; Gillette, M.A.; Paulovich, A.; Pomeroy, S.L.; Golub, T.R.; Lander, E.S.; et al. Gene set enrichment analysis: A knowledge-based approach for interpreting genome-wide expression profiles. Proc. Natl. Acad. Sci. USA 2005, 102, 15545-15550. [CrossRef]

55. Kanehisa, M.; Goto, S. KEGG: Kyoto encyclopedia of genes and genomes. Nucleic Acids Res. 2000, 28, 27-30. [CrossRef] [PubMed]

56. Fabregat, A.; Jupe, S.; Matthews, L.; Sidiropoulos, K.; Gillespie, M.; Garapati, P.; Haw, R.; Jassal, B.; Korninger, F.; May, B.; et al. The reactome pathway knowledgebase. Nucleic Acids Res. 2018, 46, D649-D655. [CrossRef] [PubMed]

57. Schaefer, C.F.; Anthony, K.; Krupa, S.; Buchoff, J.; Day, M.; Hannay, T.; Buetow, K.H. PID: The pathway interaction database. Nucleic Acids Res. 2009, 37, D674-D679. [CrossRef] 
58. Naba, A.; Clauser, K.R.; Hoersch, S.; Liu, H.; Carr, S.A.; Hynes, R.O. The matrisome: In silico definition and in vivo characterization by proteomics of normal and tumor extracellular matrices. Mol. Cell. Proteom. 2012, 11, M111.014647. [CrossRef]

59. Benjamini, Y.; Hochberg, Y. Controlling the false discovery rate: A practical and powerful approach to multiple testing. J. R. Stat. Soc. Ser. B Methodol. 1995, 57, 289-300. [CrossRef]

60. Smith, A.K.; Kilaru, V.; Kocak, M.; Almli, L.M.; Mercer, K.B.; Ressler, K.J.; Tylavsky, F.A.; Conneely, K.N. Methylation quantitative trait loci (meQTLs) are consistently detected across ancestry, developmental stage, and tissue type. BMC Genom. 2014, 15, 145. [CrossRef]

61. Bollati, V.; Galimberti, D.; Pergoli, L.; Dalla Valle, E.; Barretta, F.; Cortini, F.; Scarpini, E.; Bertazzi, P.A.; Baccarelli, A. DNA methylation in repetitive elements and Alzheimer disease. Brain Behav. Immun. 2011, 25, 1078-1083. [CrossRef] [PubMed]

62. Chang, L.; Wang, Y.; Ji, H.; Dai, D.; Xu, X.; Jiang, D.; Hong, Q.; Ye, H.; Zhang, X.; Zhou, X.; et al. Elevation of peripheral BDNF promoter methylation links to the risk of Alzheimer's disease. PLoS ONE 2014, 9, e110773. [CrossRef] [PubMed]

63. Di Francesco, A.; Arosio, B.; Falconi, A.; Micioni Di Bonaventura, M.V.; Karimi, M.; Mari, D.; Casati, M.; Maccarrone, M.; D'Addario, C. Global changes in DNA methylation in Alzheimer's disease peripheral blood mononuclear cells. Brain Behav. Immun. 2015, 45, 139-144. [CrossRef] [PubMed]

64. Nagata, T.; Kobayashi, N.; Ishii, J.; Shinagawa, S.; Nakayama, R.; Shibata, N.; Kuerban, B.; Ohnuma, T.; Kondo, K.; Arai, H.; et al. Association between DNA Methylation of the BDNF Promoter Region and Clinical Presentation in Alzheimer's Disease. Dement. Geriatr. Cogn. Dis. Extra 2015, 5, 64-73. [CrossRef] [PubMed]

65. Ji, H.; Wang, Y.; Liu, G.; Xu, X.; Dai, D.; Chen, Z.; Zhou, D.; Zhou, X.; Han, L.; Li, Y.; et al. OPRK1 promoter hypermethylation increases the risk of Alzheimer's disease. Neurosci. Lett. 2015, 606, 24-29. [CrossRef]

66. Blass, J.P.; Hanin, I.; Barclay, L.; Kopp, U.; Reding, M.J. Red blood cell abnormalities in Alzheimer disease. J. Am. Geriatr. Soc. 1985, 33, 401-405. [CrossRef]

67. Sevush, S.; Jy, W.; Horstman, L.L.; Mao, W.W.; Kolodny, L.; Ahn, Y.S. Platelet activation in Alzheimer disease. Arch. Neurol. 1998, 55, 530-536. [CrossRef]

68. Etcheberrigaray, R.; Ibarreta, D. Ionic channels and second messenger alterations in Alzheimer's disease. Relevance of studies in nonneuronal cells. Rev. Neurol. 2001, 33, 740-749. [CrossRef] [PubMed]

69. Gibson, G.E.; Huang, H.-M. Oxidative processes in the brain and non-neuronal tissues as biomarkers of Alzheimer's disease. Front. Biosci. 2002, 7, d1007-d1015. [CrossRef]

70. Catricala, S.; Torti, M.; Ricevuti, G. Alzheimer disease and platelets: How's that relevant. Immun. Ageing 2012, 9, 20. [CrossRef]

71. Kaminsky, Y.G.; Reddy, V.P.; Ashraf, G.M.; Ahmad, A.; Benberin, V.V.; Kosenko, E.A.; Aliev, G. Age-related defects in erythrocyte 2,3-diphosphoglycerate metabolism in dementia. Aging Dis. 2013, 4, 244-255. [CrossRef] [PubMed]

72. Hokama, M.; Oka, S.; Leon, J.; Ninomiya, T.; Honda, H.; Sasaki, K.; Iwaki, T.; Ohara, T.; Sasaki, T.; LaFerla, F.M.; et al. Altered expression of diabetes-related genes in Alzheimer's disease brains: The Hisayama study. Cereb. Cortex 2014, 24, 2476-2488. [CrossRef] [PubMed]

73. Hannon, E.; Weedon, M.; Bray, N.; O’Donovan, M.; Mill, J. Pleiotropic effects of trait-associated genetic variation on DNA methylation: Utility for refining GWAS loci. Am. J. Hum. Genet. 2017, 100, 954-959. [CrossRef] [PubMed]

74. Li, H.; Wetten, S.; Li, L.; St Jean, P.L.; Upmanyu, R.; Surh, L.; Hosford, D.; Barnes, M.R.; Briley, J.D.; Borrie, M.; et al. Candidate single-nucleotide polymorphisms from a genomewide association study of Alzheimer disease. Arch. Neurol. 2008, 65, 45-53. [CrossRef]

75. Han, M.-R.; Schellenberg, G.D.; Wang, L.-S. Alzheimer's Disease Neuroimaging Initiative Genome-wide association reveals genetic effects on human $A \beta 42$ and $\tau$ protein levels in cerebrospinal fluids: A case control study. BMC Neurol. 2010, 10, 90. [CrossRef]

76. Beecham, G.W.; Hamilton, K.; Naj, A.C.; Martin, E.R.; Huentelman, M.; Myers, A.J.; Corneveaux, J.J.; Hardy, J.; Vonsattel, J.-P.; Younkin, S.G.; et al. Genome-wide association meta-analysis of neuropathologic features of Alzheimer's disease and related dementias. PLoS Genet. 2014, 10, e1004606. [CrossRef]

77. Sherva, R.; Tripodis, Y.; Bennett, D.A.; Chibnik, L.B.; Crane, P.K.; de Jager, P.L.; Farrer, L.A.; Saykin, A.J.; Shulman, J.M.; Naj, A.; et al. Genome-wide association study of the rate of cognitive decline in Alzheimer's disease. Alzheimers Dement. 2014, 10, 45-52. [CrossRef] 
78. Stelzer, G.; Rosen, N.; Plaschkes, I.; Zimmerman, S.; Twik, M.; Fishilevich, S.; Stein, T.I.; Nudel, R.; Lieder, I.; Mazor, Y.; et al. The GeneCards suite: From gene data mining to disease genome sequence analyses. Curr. Protoc. Bioinform. 2016, 54, 1.30.1-1.30.33. [CrossRef]

79. Keller, M.F.; Reiner, A.P.; Okada, Y.; van Rooij, F.J.A.; Johnson, A.D.; Chen, M.-H.; Smith, A.V.; Morris, A.P.; Tanaka, T.; Ferrucci, L.; et al. Trans-ethnic meta-analysis of white blood cell phenotypes. Hum. Mol. Genet. 2014, 23, 6944-6960. [CrossRef]

80. Ahn, H.; Kang, S.G.; Yoon, S.; Ko, H.-J.; Kim, P.-H.; Hong, E.-J.; An, B.-S.; Lee, E.; Lee, G.-S. Methylene blue inhibits NLRP3, NLRC4, AIM2, and non-canonical inflammasome activation. Sci. Rep. 2017, 7, 12409. [CrossRef]

81. Freeman, L.C.; Ting, J.P.-Y. The pathogenic role of the inflammasome in neurodegenerative diseases. J. Neurochem. 2016, 136 (Suppl. 1), 29-38. [CrossRef] [PubMed]

82. Liu, L.; Chan, C. The role of inflammasome in Alzheimer's disease. Ageing Res. Rev. 2014, 15, 6-15. [CrossRef] [PubMed]

83. Oz, M.; Lorke, D.E.; Petroianu, G.A. Methylene blue and Alzheimer's disease. Biochem. Pharmacol. 2009, 78, 927-932. [CrossRef] [PubMed]

84. Wu, P.-J.; Liu, H.-Y.; Huang, T.-N.; Hsueh, Y.-P. AIM2 inflammasomes regulate neuronal morphology and influence anxiety and memory in mice. Sci. Rep. 2016, 6, 32405. [CrossRef] [PubMed]

85. Tadiboyina, V.T.; Rupar, A.; Atkison, P.; Feigenbaum, A.; Kronick, J.; Wang, J.; Hegele, R.A. Novel mutation in DGUOK in hepatocerebral mitochondrial DNA depletion syndrome associated with cystathioninuria. Am. J. Med. Genet. A 2005, 135, 289-291. [CrossRef]

86. Lunnon, K.; Keohane, A.; Pidsley, R.; Newhouse, S.; Riddoch-Contreras, J.; Thubron, E.B.; Devall, M.; Soininen, H.; Kłoszewska, I.; Mecocci, P.; et al. Mitochondrial genes are altered in blood early in Alzheimer's disease. Neurobiol. Aging 2017, 53, 36-47. [CrossRef] [PubMed]

87. Querfurth, H.W.; LaFerla, F.M. Alzheimer's Disease. N. Engl. J. Med. 2010, 362, 329-344. [CrossRef]

88. Braak, H.; Braak, E. Staging of Alzheimer's disease-related neurofibrillary changes. Neurobiol. Aging 1995, 16, 271-278; discussion 278-284. [CrossRef]

89. Ansoleaga, B.; Jové, M.; Schlüter, A.; Garcia-Esparcia, P.; Moreno, J.; Pujol, A.; Pamplona, R.; Portero-Otín, M.; Ferrer, I. Deregulation of purine metabolism in Alzheimer's disease. Neurobiol. Aging 2015, 36, 68-80. [CrossRef]

90. Yang, W.; Tang, H.; Zhang, Y.; Tang, X.; Zhang, J.; Sun, L.; Yang, J.; Cui, Y.; Zhang, L.; Hirankarn, N.; et al. Meta-analysis followed by replication identifies loci in or near CDKN1B, TET3, CD80, DRAM1, and ARID5B as associated with systemic lupus erythematosus in Asians. Am. J. Hum. Genet. 2013, 92, 41-51. [CrossRef]

91. Wotton, C.J.; Goldacre, M.J. Associations between specific autoimmune diseases and subsequent dementia: Retrospective record-linkage cohort study, UK. J. Epidemiol. Community Health 2017, 71, 576-583. [CrossRef] [PubMed]

92. Wirz, K.T.S.; Bossers, K.; Stargardt, A.; Kamphuis, W.; Swaab, D.F.; Hol, E.M.; Verhaagen, J. Cortical beta amyloid protein triggers an immune response, but no synaptic changes in the APPswe/PS1dE9 Alzheimer's disease mouse model. Neurobiol. Aging 2013, 34, 1328-1342. [CrossRef] [PubMed]

93. Yin, Z.; Raj, D.; Saiepour, N.; Van Dam, D.; Brouwer, N.; Holtman, I.R.; Eggen, B.J.L.; Möller, T.; Tamm, J.A.; Abdourahman, A.; et al. Immune hyperreactivity of A $\beta$ plaque-associated microglia in Alzheimer's disease. Neurobiol. Aging 2017, 55, 115-122. [CrossRef] [PubMed]

94. Mendes Maia, T.; Gogendeau, D.; Pennetier, C.; Janke, C.; Basto, R. Bug22 influences cilium morphology and the post-translational modification of ciliary microtubules. Biol. Open 2014, 3, 138-151. [CrossRef]

95. Baird, F.J.; Bennett, C.L. Microtubule defects \& neurodegeneration. J. Genet. Syndr. Gene 2013, 4, 203. [CrossRef]

96. Brunden, K.R.; Lee, V.M.-Y.; Smith, A.B.; Trojanowski, J.Q.; Ballatore, C. Altered microtubule dynamics in neurodegenerative disease: Therapeutic potential of microtubule-stabilizing drugs. Neurobiol. Dis. 2017, 105, 328-335. [CrossRef]

97. Atamna, H.; Frey, W.H. Mechanisms of mitochondrial dysfunction and energy deficiency in Alzheimer's disease. Mitochondrion 2007, 7, 297-310. [CrossRef]

98. Rodríguez, J.J.; Verkhratsky, A. Neurogenesis in Alzheimer's disease. J. Anat. 2011, 219, 78-89. [CrossRef]

99. Hroudová, J.; Singh, N.; Fišar, Z. Mitochondrial dysfunctions in neurodegenerative diseases: Relevance to Alzheimer's disease. Biomed. Res. Int. 2014, 2014, 175062. [CrossRef] 
100. Li, Y.; Sun, H.; Chen, Z.; Xu, H.; Bu, G.; Zheng, H. Implications of GABAergic Neurotransmission in Alzheimer's Disease. Front. Aging Neurosci. 2016, 8, 31. [CrossRef]

101. Tucsek, Z.; Noa Valcarcel-Ares, M.; Tarantini, S.; Yabluchanskiy, A.; Fülöp, G.; Gautam, T.; Orock, A.; Csiszar, A.; Deak, F.; Ungvari, Z. Hypertension-induced synapse loss and impairment in synaptic plasticity in the mouse hippocampus mimics the aging phenotype: Implications for the pathogenesis of vascular cognitive impairment. GeroScience 2017, 39, 385-406. [CrossRef] [PubMed]

102. Schetters, S.T.T.; Gomez-Nicola, D.; Garcia-Vallejo, J.J.; Van Kooyk, Y. Neuroinflammation: Microglia and T Cells get ready to tango. Front. Immunol. 2018, 8, 1905. [CrossRef] [PubMed]

103. Cao, W.; Zheng, H. Peripheral immune system in aging and Alzheimer's disease. Mol. Neurodegener. 2018, 13, 51. [CrossRef] [PubMed]

104. Chatterjee, S.; Mudher, A. Alzheimer's disease and type 2 diabetes: A critical assessment of the shared pathological traits. Front. Neurosci. 2018, 12, 383. [CrossRef] [PubMed]

(C) 2020 by the authors. Licensee MDPI, Basel, Switzerland. This article is an open access article distributed under the terms and conditions of the Creative Commons Attribution (CC BY) license (http://creativecommons.org/licenses/by/4.0/). 